\title{
BERNARDO DE BALBUENA, EL QUE EN BUEN PUNTO NACIÓ $^{1}$
}

\author{
Martín Zulaica López \\ Universidad Rey Juan Carlos \\ Madrid, España \\ martin.zulaica@urjc.es \\ Alberto Montaner \\ Universidad de Zaragoza \\ Zaragoza, España \\ amonta@unizar.es

\section{RESUMEN / ABSTRACT}

Este artículo tiene como objetivo aclarar la fecha de nacimiento del poeta español del Siglo de Oro, Bernardo de Balbuena, a partir de la interpretación de un pasaje de su poema épico El Bernardo, en el que se presenta un elemento notable de su carta astral natal: su nacimiento bajo la gran conjunción de 1563. Tras compilar toda la información documental disponible del período, se presenta un panorama sobre la evolución de la doctrina de las grandes conjunciones y se evalúa la estrategia de autodignificación del poeta, mediante la indicación de su nacimiento bajo este fenómeno astrológico y de su doble relación, tanto astral como onomástica, con su héroe poético.

Palabras clave: Bernardo de Balbuena, fecha de nacimiento, astrología, conjunción magna, autorrepresentación, autorreflexividad.

\section{BERNARDO DE BALBUENA, WHO WAS BORN AUSPICIOUSLY}

This paper aims to clarify the date of birth of the Spanish Golden Age poet, Bernardo de Balbuena, based on the interpretation of a passage from his epic poem El Bernardo in which a

$1 \quad$ El presente trabajo se enmarca dentro del Proyecto de I+D del Programa Estatal de Generación de conocimiento (MCIU/FEDER) PGC-2018-095757-B-100: Magia, Épica e Historiografia Hispánicas: Relaciones Literarias y Nomológicas II. 
remarkable element of his natal astral chart is presented: his birth under the great conjunction of 1563. After compiling all the available documentary information from the period, it presents a panorama on the evolution of the doctrine of the great conjunctions and evaluates the poet's strategy of self-dignification through signaling of his birth under this astrological phenomenon and his double relationship, both astral and onomastic, with his poetic hero.

KEYWORDS: Bernardo de Balbuena, birth date, astrology, great conjunction, self-representation, self-reflexivity.

Recepción: 25/07/2020

Aprobación: 10/05/2021

La trayectoria vital de Bernardo de Balbuena fue prácticamente desconocida en su totalidad hasta bien avanzada la primera mitad del siglo XX, cuando John Van Horne, en 1940, dedicó la primera biografía de investigación al poeta² Gracias a sus desvelos logramos tener un retrato atento de su vida y escritura desde finales del siglo XVI, en el que vemos al poeta ganando premios literarios como colegial de la lozana universidad mexicana y ocupando diferentes cargos del clero regular en Nueva Galicia. También gracias a él conocimos a su padre, un letrado que viajó a las Indias con la esperanza de enriquecerse y que allí logró ejercer puestos de responsabilidad al servicio de la Corona, a pesar de verse envuelto en un sonado pleito que lo apartó de su cargo por un tiempo. Supimos de los avatares de su promoción eclesiástica hasta el obispado de Puerto Rico, pasando antes por la abadía de Jamaica y cómo la logró, parece que merced a sus servicios literarios, en un viaje a la Península Ibérica en que se dio a conocer a los principales ingenios del momento, en especial a Lope de Vega. No obstante, sus primeros años de vida continuaban siendo una incógnita envuelta por la penumbra de las suposiciones, como destaca Terukina (2), y así ha seguido siéndolo en buena medida a pesar de las últimas aportaciones de Zulaica (2021). ${ }^{3}$ Esto afectaba, en concreto, a su fecha de nacimiento, dato que, además de su interés intrínseco, posee, como veremos, una especial relevancia personal y literaria.

\footnotetext{
2 Previamente deben destacarse los perfiles biográficos breves que elaboraron Fernández Juncos (1883), Vasco (1890-1895) y Medina (1922).

3 En dicho trabajo se expusieron brevemente algunas de las conclusiones alcanzadas en este y aquí analizadas de forma pormenorizada.
} 


\section{LA INFORMACIÓN DOCUMENTAL}

Ya en el siglo XVII el cronista Gil González Dávila había consignado los nombres de los padres del poeta-Bernardo de Balbuena y Francisca Sánchez de Velasco-y de su lugar de nacimiento -Valdepeñas, en la actual provincia de Ciudad Real-, pero la noticia no encontró gran resonancia y cayó en el olvido ${ }^{4}$. A comienzos del siglo XIX, cuando Quintana, en el contexto del enfrentamiento hispano-francés de la Guerra de Independencia, reimprimió El Bernardo, el poema épico de Balbuena, se conocía su patria chica por diversas fuentes. Ante todo, por una alusión en calambur incluida en la propia epopeya: "De aquel valle amenísimo de peñas, / [...] / un cisne nacerá de alas pequeñas" (Balbuena, El Bernardo XVI, 148. Las cursivas son nuestras) ${ }^{5}$. Pero también por algunas de las composiciones encomiásticas que acompañaban a sus obras (Van Horne, "El nacimiento" 162-163). Y, finalmente, por Nicolás Antonio, que lo había señalado en su fundamental Bibliotheca Hispana nova: "D. Bernardus de Balbuena, oppidum Valdepeñas, diœcesis Toletanæ habuit patriam" (1:221).

Con estos conocimientos se trató de documentar el nacimiento de Balbuena en la parroquial de Valdepeñas, donde se localizó la partida de bautismo de cierto Hernando de Balbuena, hijo de Gregorio de Villanueva y Luisa de Balbuena, fechada el 22 de noviembre de 1568. Desde esta segunda edición de El Bernardo se atribuyó al poeta esta partida de bautismo ${ }^{6}$, que luego se supo de un familiar suyo ${ }^{7}$, dando lugar a una confusión sobre su fecha de nacimiento y los nombres de sus padres que aún sigue siendo habitual.

$4 \quad$ González Dávila (1: 292). La mayor parte de la información sobre Puerto Rico que empleó este autor provenía de una relación que preparó por encargo suyo Torres Vargas en 1647 (inédita hasta 1854), pero en ella, a pesar de lo esperable, no figuran los nombres de los padres de Balbuena, cuyo origen desconocemos.

5 Adviértase que en el documento que citamos en la nota 8 aparece varias veces la grafía "Val de Peñas".

6 Quintana (I) afirma haber recabado información, sin duda alguna este dato, "consultando el archivo de la iglesia parroquial de Valdepeñas" (III).

7 El error fue advertido por primera vez por Vasco (Valdepeñas 185), que anteriormente había aceptado esta fecha como correcta (Ilustres 145), y recordado por Van Horne ("E1 nacimiento" 160). Todavía hoy es frecuente encontrar en la bibliografía académica como fecha de nacimiento la de la partida de bautismo de este familiar del poeta, o incluso una combinación de esta - de la que se toman día y mes- con alguno de los años señalados como posibles a partir de las investigaciones de Van Horne, esto es, 1561 o 1562. Del mismo modo, 
A mediados del siglo pasado, el descubrimiento de una solicitud de licencia hecha por Bernardo de Balbuena para pasar a Nueva España en abril de 1584 clarificó en parte la situación ${ }^{8}$. Este documento permitía confirmar que el poeta había nacido en Valdepeñas (Ciudad Real, España) y ofrecía una fecha aproximada de nacimiento, expresada en las señas de identidad que, ante el alcalde o juez municipal Pedro Sánchez de Santacruz, declaró, el día 8 de abril, el mismo Balbuena: "de cómo es natural desta villa de Valdepeñas y nasció y se crio en ella, y de cómo es mozo de hasta veinte y un años" (Figura 1). Estos datos fueron ratificados por dos de los cuatro vecinos de Valdepeñas que actuaron como testigos, Bernardino de Cantos y Pedro Moreno, señalando que su edad era de veintiún años "poco más o menos" (ff. [3]v y [4]r). Así, el documento, además de permitir una estimación sobre la edad, demostraba que Balbuena se había criado en la península, contra lo que deducía Van Horne de la siguiente indicación de El Bernardo ${ }^{10}$ :

Ya en mi esperanza el tierno fruto veo de dos mirtos salir parto fecundo,

siguen atribuyéndoseles erróneamente a sus padres los nombres que figuran en esta partida, o bien se unen los de Bernardo de Balbuena el Viejo y Luisa de Balbuena.

Archivo General de Indias (= AGI), Indiferente, 2061, n. ${ }^{\circ} 153$ (ed. Montaner y Navarro 743-77, doc. 1). Este documento fue localizado y publicado de forma independiente y, en ambos casos, incompleta por Porras Muñoz, en 1950, y por Rubio Mañé ("Bernardo de Balbuena"), en 1960. Esta información la han difundido trabajos fundamentales sobre Balbuena, como la biografía de Rojas Garcidueñas (8-16), a partir de su segunda edición (de 1982). Es, pues, de lamentar que la entrada dedicada a Balbuena por González Boixo en una obra tan consultada como el Diccionario Biográfico Español, de la Real Academia de la Historia, afirme aún que el futuro poeta pasó a México, con apenas dos años de edad, en 1564, cuando su padre regresó a Nueva Galicia (entre otras inexactitudes). Por su parte, Rubio Mañé, en un segundo artículo, "Noticias biográficas" (de 1966), atribuyó erróneamente a Balbuena cierta documentación relativa al escritor Bernardo de la Vega, que presenta varios paralelos con Balbuena y sobre el cual puede verse Cacho Casal.

9 AGI, Indiferente, 2061, n. ${ }^{\circ}$ 153, f. [3]v (el subrayado es nuestro). Todas las citas se dan en grafía regularizada, pero respetando siempre la fonología del texto, siguiendo los criterios expuestos por Zulaica en la edición de El Bernardo (1: 53).

10 "Lo más probable es que el niño Balbuena no pasara en Valdepeñas tiempo suficiente para recibir impresiones directas. El padre volvió a la Nueva España en 1564. No se nombra en la licencia al hijo que tendría dos años. Sin embargo no es imposible que le acompañara. Parecería al paso más lógico y práctico. Una estrofa del Bernardo (XVI, 149) sugiere que atravesó el océano en edad muy tierna, que podría ser en compañía de su padre o poco después" (Van Horne, Bernardo de Balbuena 26). 
y del sol imitando el gran rodeo los golfos desvolver del mar profundo; y por colmo a mi altísimo deseo cruzar le veo el viejo y nuevo mundo, juntando de ambos para el grave acento lo de mayor sustancia y fundamento (XVI, 149).

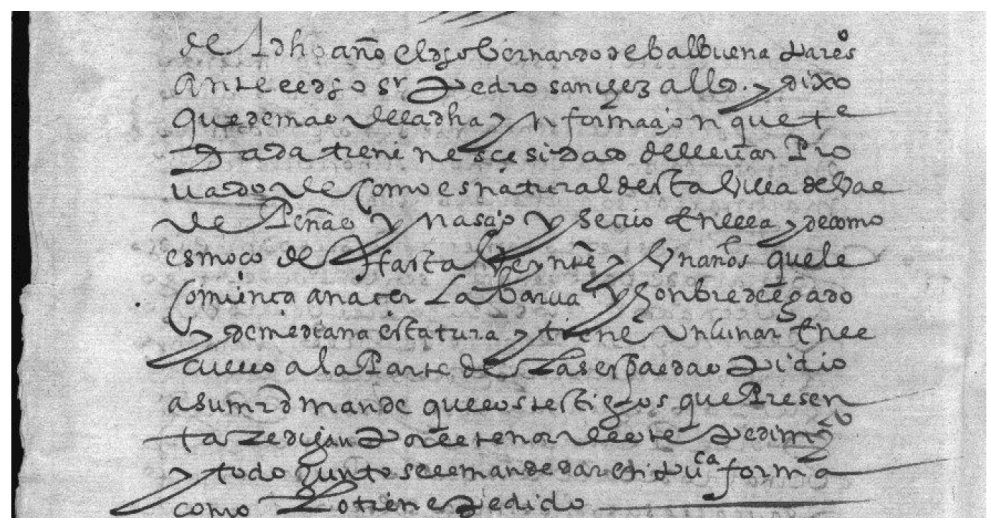

Figura 1. Patria chica, edad (el 8 / IV / 1584) y señas de identidad de Bernardo de Balbuena (AGI, Indiferente, 2061, № 153, f. [3]v).

Junto a la información aportada por este documento ha de considerarse la de otros dos localizados por Van Horne: el testimonio de Balbuena en una probanza de su amigo Pedro Altamirano, hecha en Guadalajara de Nueva Galicia el 8 de noviembre de 1595 (Van Horne, "Documentos" n. ${ }^{\circ}$ 12, "El nacimiento" 164-165, Bernardo 16), y una información de parte de Bernardo de Balbuena, abad de la Villa de la Vega, en Jamaica ${ }^{11}$, iniciada el 2 de noviembre de 1611 y concluida el 7 de febrero de 1612 (Van Horne, "Documentos" n. ${ }^{\circ}$

11 "Abad" en la segunda acepción de "Autoridades": "se llama también el superior y cabeza de algunas iglesias colegiales, como la de Alcalá la Real, Lerma, y otras; y asimismo se da este nombre y título de abad a los superiores de algunas iglesias, en que sirven canónigos reglares, como las de San Isidro de León, Santa María de Arbas, Covadonga y otras" (Real Academia Española 1:3). 
21, "El nacimiento" 165, Bernardo 16). En su deposición como testigo de la probanza del difunto licenciado Pedro Altamirano, oidor de la Real Audiencia de Guadalajara, hecha a petición de su viuda, Balbuena es presentado como "clérigo presbítero, vecino desta dicha ciudad" y él declara "que es de edad de treinta y tres años, poco más o menos" ${ }^{\prime 2}$. En la información de parte, Juan Ortiz de Sandoval, regidor de la Villa de Jamaica y procurador de Balbuena, pide que se pregunte a los testigos "si saben que el dicho dotor don Bernaldo de Balbuena será de edad de sincuenta $[$ sic $]$ años, poco más o menos"13. En sus deposiciones, los testigos, que conocen de modo bastante superficial a Balbuena, se limitan, en este punto, a ratificar, siempre con expresiones de cautela y el inevitable "poco más o menos", lo indicado en el cuestionario de Ortiz de Sandoval, y así lo ratifica el parecer de la Real Audiencia, como recoge la siguiente tabla ${ }^{14}$ :

\begin{tabular}{|l|l|l|}
\hline Fecha & Nombre del testigo & Declaración \\
\hline $1611 /$ XI / & Manuel de Grado, vecino. & $\begin{array}{l}\text { "dijo este testigo que le parese } \\
\text { será el dicho abad de la edad } \\
\text { que dice la pregunta" (11r). }\end{array}$ \\
\cline { 2 - 3 } & Francisco Caldera, vecino & $\begin{array}{l}\text { "dijo este testigo que le parese } \\
\text { que el dicho dotor don Bernaldo } \\
\text { Balbuena será de la edad que } \\
\text { la pregunta dice" (12r). }\end{array}$ \\
\hline $1611 /$ XI / 4 & Manuel Luis, vecino & $\begin{array}{l}\text { "dijo este testigo que será el } \\
\text { dicho dotor don Bernaldo de } \\
\text { Balbuena, abad de Jamaica, } \\
\text { de la edad contenida en la } \\
\text { pregunta, poco más o menos" } \\
\text { (13r). }\end{array}$ \\
\hline
\end{tabular}

12 AGI, Guadalajara, 48, n. ${ }^{\circ}$ 17, f. $13 \mathrm{r}-\mathrm{v}$ (ed. Montaner y Navarro 758, doc. 5)

13 AGI, Santo Domingo, 19, n. ${ }^{\circ}$ 3, f. 2 v (ed. Montaner y Navarro 782, doc. 11)

14 Tomada de Montaner y Navarro (786, doc. 11), con la adición del parecer de la Audiencia (787). Las fechas están dadas en orden inverso, al estilo diplomático. 


\begin{tabular}{|c|c|c|}
\hline $1611 / \mathrm{XI} / 5$ & Fray Martín Maldonado, O.P. & $\begin{array}{l}\text { "dijo este testigo que trató } \\
\text { y comunicó al dicho abad el } \\
\text { tiempo que este testigo estuvo } \\
\text { en la dicha isla de Jamaica, } \\
\text { que sería sinco o seis meses, } \\
\text { y la parese será el dicho abad } \\
\text { de la edad que refiere esta } \\
\text { pregunta" (14r). }\end{array}$ \\
\hline \multirow[t]{2}{*}{1612 / I / 10} & $\begin{array}{l}\text { Pedro de Bardecí y Mella, } \\
\text { arcediano de la catedral de } \\
\text { Santo Domingo }\end{array}$ & $\begin{array}{l}\text { "dijo este testigo que le parece } \\
\text { que el dicho dotor don Bernaldo } \\
\text { de Balbuena será de edad de } \\
\text { sincuenta años, poco más o } \\
\text { menos" }(15 \mathrm{v}) \text {. }\end{array}$ \\
\hline & $\begin{array}{l}\text { Francisco Talaverano Mansera, } \\
\text { deán de la catedral de Santo } \\
\text { Domingo }\end{array}$ & $\begin{array}{l}\text { "dijo que le parese a este testigo } \\
\text { será el dicho abad de más de } \\
\text { cuarenta e sinco años, poco } \\
\text { más o menos" (16r). }\end{array}$ \\
\hline \multirow[t]{2}{*}{1612 / II / 17} & Diego de Villafane, vecino & $\begin{array}{l}\text { "dijo este testigo que en su } \\
\text { aspeto de dicho abad pareçía } \\
\text { ser de la edad contenida en la } \\
\text { pregunta, poco más o menos" } \\
(17 \mathrm{r}) \text {. }\end{array}$ \\
\hline & $\begin{array}{l}\text { Gaspar de Aspilhueta, relator } \\
\text { de la Real Audiencia }\end{array}$ & $\begin{array}{l}\text { "parecía de la edad que la } \\
\text { pregunta dice, poco más o } \\
\text { menos" (18r). }\end{array}$ \\
\hline 1612 / XI / 15 & $\begin{array}{l}\text { El presidente y los oidores de } \\
\text { la Real Audiencia }\end{array}$ & $\begin{array}{l}\text { "El doctor don Bernardo de } \\
\text { Balbuena, abad de la isla } \\
\text { Jamaica. como parece por esta } \\
\text { información, será de edad de } \\
\text { cincuenta años y habrá dos años } \\
\text { fue a servir su dignidad" (19r). }\end{array}$ \\
\hline
\end{tabular}

Como puede apreciarse, la mayoría de los declarantes remiten vagamente a una cifra redonda, mientras que uno de ellos la rebaja, por lo que la información resulta menos precisa, generando una horquilla cronológica de más de un lustro, que va de 1561 a 1566 . En cambio, los dos primeros documentos señalan períodos más concretos. Habida cuenta, además, de que en ellos interviene directamente Balbuena, lo que no ocurre en la información de 
1611-1612, resulta preferible prescindir de esta última a la hora de calcular la fecha de nacimiento del poeta.

Antes de echar las cuentas de rigor, es preciso hacer una estimación del grado de exactitud de este tipo de menciones, para lo que podemos utilizar dos puntos de comparación. Por un lado, como acabamos de ver, el 15 de noviembre de 1612, los magistrados de la Real Audiencia de Santo Domingo estiman en unos dos años el tiempo transcurrido desde que Balbuena se embarcó hacia Jamaica. Por la licencia correspondiente, consta que fue consignado en el registro de pasajeros, junto a un clérigo acompañante, para embarcar en la nao del maestre Alonso Sánchez de Espinosa, el 19 de enero de $1610^{15}$. Así pues, entre este suceso y aquella apreciación habían pasado realmente 2 años, 8 meses y 21 días. Por otro lado, contamos con la indicación contenida en la información del licenciado Altamirano, en la que su viuda declara, el 6 de noviembre de 1595, que "habrá catorce años que fue proveído por oidor desta Real Audiencia de Guadalajara" ${ }^{16}$. Pues bien, dicho nombramiento se hizo por Real Cédula de 27 de enero de $1581^{17}$, es decir, 14 años, 9 meses y 10 días antes. En consecuencia, ese "poco más o menos" indicado por los testigos en el caso de Balbuena puede estimarse en un margen de un año arriba o abajo ${ }^{18}$.

Esto proporciona sendos arcos temporales de dos años centrados en las respectivas fechas dentro de cada uno de los cuales el correspondiente testimonio documental resulta verídico. En el documento de 1584, el intervalo resultante corre del 9 de abril de 1562 al 7 de abril de 1564; en el de 1595, del 9 de noviembre de 1561 al 7 de noviembre de 1563. La intersección entre

15 AGI, Contratación, 5318, № 2, R. 30, f. [1]r (ed. Montaner y Navarro 764, doc. 6; cf. Van Horne, "Documentos" 860, n. $\left.{ }^{\circ} 17-18\right)$.

16 AGI, Guadalajara, 48, № 17, f. 3v (ed. Montaner y Navarro 754, doc. 5).

17 AGI, Guadalajara, 230, L. 1, ff. 372r-374r, y Contratación, 5788, L. 1, f. 145r-v.

18 Estrictamente hablando, el lapso temporal en torno a cada fecha en el que la afirmación de ambos documentos sería literalmente cierta abarca desde un día, antes o después, hasta dos años menos un día, antes o después. Ahora bien, lo que aquí interesa en la práctica son los extremos del intervalo. Denotando por $n$ la fecha de nacimiento de Balbuena; por $d$, la data de cada documento; por $e$, la correspondiente edad expresada en ellos, y por $f$, la fecha deducible en virtud de la fórmula $f=d-e$, el intervalo abierto queda determinado por la fórmula $n=$ ] $f \pm 365$ [ (es decir, por $f$ más/menos un año, expresado en días), constituyendo el intervalo real $I$ o parte de $\mathbb{R}$ que satisface la condición $\{n \in \mathbb{R} \mid f-365<n<f+365\}$. Dado que cada documento presupone su propio intervalo, $I$ e $I^{\prime}$, puede restringirse la condición precitada a la pertenencia de $n$ a la intersección de los mismos: $n \in I \cap I^{\prime}$. 
ambos, por último, determina el intervalo en que las afirmaciones de ambos testimonios serían ciertas, el cual va del 9 de abril de 1562 y al 7 de noviembre de 1563 (Figura 2). Habiendo, pues, nacido en este arco cronológico, Bernardo de Balbuena tendría, en la fecha del primer documento ( 8 de abril de 1584), entre 21 años más 7 meses y 22 años; y en la del segundo ( 8 de noviembre de 1595), entre 32 años y 33 años más 7 meses.

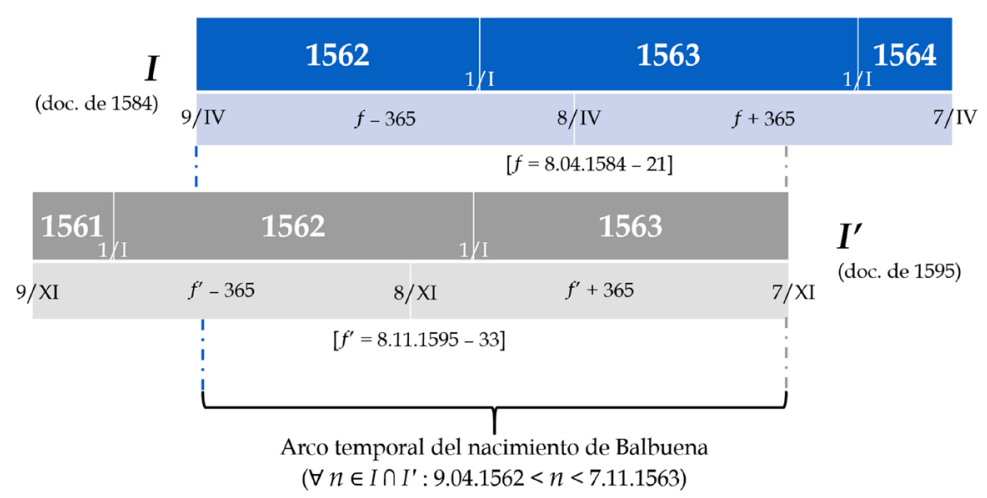

Figura 2. Diagrama para la determinación del intervalo cronológico del nacimiento de Balbuena a partir de la documentación conservada.

\section{UNA CLAVE ASTRONÓMICA: LA CONJUNCIÓN MAGNA}

A la documentación ya analizada es posible añadir un dato nunca antes valorado por la crítica, el cual permite corroborar y, acaso, precisar la fecha de nacimiento de Balbuena. En el libro decimoséptimo de El Bernardo se relata una visión onírica de Bernardo del Carpio en la que el dios Apolo, en pago por ciertos servicios que el héroe realiza en el Parnaso, le profetiza cómo, pasados ochos siglos, surgirá un homónimo que cantará sus hazañas sacándolas del olvido (XVII, 85-89). Ese cantor no será otro que el propio Bernardo de Balbuena, como más tarde señala el poeta: "¿Si habla -dijede mí esta profecía?” (XVII, 105, 3; cf. Triviños 324-25). Pues bien, en 
su parlamento, el dios Apolo desarrolla un aspecto astronómico de gran relevancia en este contexto:

85. Altivos hechos del valor de España en cuadros de oro daban resplandores, cuyos colosos, de grandeza estraña, de los más altos quedan superiores, adonde al bronce que la vista engaña su rica estatua dio nuevos primores, con los diestros buriles de la Fama, que a eterna duración la suya llama. 86. "Esta-le dijo Apolo- en nombre eterno aquí del tuyo queda consagrada, a quien tu duro brazo, ahora tierno, dejará de grandezas coronada; $\mathrm{y}$, aunque entre nieblas de un prolijo invierno, por estos ocho siglos olvidada, sin la luz volará que ahora tiene, ni esto te entibie ni tu espada enfrene.

87. Que apenas de los dos planetas de oro la magna conjunción, que ayer se hizo en el frío Sagitario, al pueblo moro favorable y su cetro advenedizo, a España entero volverá el tesoro que su infeliz concurso le deshizo, cuando segunda vez tu heroico nombre como tu espada ahora el mundo asombre. 88. Digo que, cuando el orbe goce de esta séptima conjunción las maravillas y España, en su primer grandeza puesta, de una silla real haga sus sillas de un ramo de laurel de esta floresta, en una nacerá de dos Castillas, a vueltas de otros cisnes, una pluma que a tus hechos dará compendio y suma. 89. Entonces volverá florido al mundo tu nombre con el suyo renovado, de los senos sacando del profundo 
lo que de ti allí tiene escrito el Hado.

Tú serás el primero, él el segundo, ambos de un mismo nombre y un cuidado, tú en hacer con tu espada maravillas, y él con su humilde pluma en escrebillas (XVII, 85-89).

Dada la habitual complejidad de Balbuena, aunque el sentido general de estos versos resulta bastante evidente, no lo son todos sus detalles, que es preciso afinar para la discusión subsiguiente. Nos permitimos, pues, ofrecer la siguiente paráfrasis:

85. Las grandes hazañas de los valerosos españoles brillaban representadas en escenas doradas, cuyos colosales héroes, de asombrosa estatura, superan a los mayores de otras naciones [en tamaño y heroísmo], y entre las cuales su preciosa estatua [la de Bernardo] otorgó al bronce nuevas cualidades artísticas, mediante los hábiles cinceles de la Fama, la cual [sc. la estatua de Bernardo] promueve la eterna duración de su fama.

86. Le dijo Apolo [a Bernardo]: "Esta estatua queda aquí consagrada como recuerdo eterno de tu nombre, la cual dejará coronada de hazañas tu fuerte brazo, aunque ahora sea débil por tu juventud, de modo que, aunque tu fama vaya a ser olvidada durante los próximos ocho siglos $^{19}$, volando sin la luminosidad que tiene ahora [es decir, en vida del héroe] y envuelta en la oscuridad de un dilatado invierno, esto no debe hacerte perder el ánimo ni refrenar tu espada.

87. Pues, en cuanto la conjunción magna de los dos brillantes planetas [Júpiter y Saturno] (la misma que se produjo hace un tiempo en Sagitario de modo favorable al Islam y a su usurpado dominio) devuelva a España toda la grandeza que su infausta reunión le arrebató, entonces tu heroico nombre [el de Bernardo, por Bernardo de Balbuena] asombrará al mundo de nuevo, al igual que tu espada lo hace ahora.

88. Quiero decir que, cuando el mundo disfrute de las maravillas de según lo que él mismo explica en el prólogo sobre la materia de su poema: "sin dejar por eso de contar su nacimiento y origen, sus hazañas y decendencia, cuanto de él y de sus sucesores han escrito los historiadores más graves de nuestra nación, hasta ochocientos años después de su muerte" (1: 78). 
esta séptima conjunción magna y España, devuelta a su primitiva grandeza, convierta sus múltiples tronos en uno solo fabricado en laurel [imperial $]^{20}$, nacerá en una de ambas Castillas, junto con otros cisnes [= poetas], uno cuya pluma hará un cumplido resumen de tus hechos. 89. Entonces tu nombre volverá, ennoblecido, al mundo, renovado junto con el suyo [por llamarse también Bernardo], sacando de las honduras del abismo [del olvido] lo que el Hado tiene escrito sobre ti [que ahora es lo que te destina el futuro, pero entonces serán los logros de tu pasado]. Tú serás el primer Bernardo y él, el segundo, compartiendo ambos, no solo el nombre, sino también el propósito: tú el de realizar acciones maravillosas con tu espada y él el de describirlas con su humilde pluma.

El episodio en que se inserta este pasaje ha sido objeto de estudio en varias ocasiones, incidiendo sobre la identidad literaria de Balbuena, en especial, de forma muy aguda, por Friedlein, en un epígrafe sobre el fenómeno de la autorreflexividad (332-342). Sin embargo, nadie ha reparado hasta ahora en que el pasaje incluye una clave astronómica de gran importancia, tanto para la determinación de la fecha del nacimiento de Balbuena, como para el mecanismo de correspondencias que lo convierte en poco menos que el cantor predestinado de las proezas del héroe hispánico. Esa clave es el fenómeno identificado en el verso 86.2 como "la magna conjunción".

De modo genérico, las coniunctiones magnce consisten en la reunión (en el mismo grado de un mismo signo zodiacal) de al menos dos de los planetas superiores, esto es, de los que, vistos desde la Tierra, orbitan más allá del Sol, en las esferas quinta, la de Marte $=\hat{O}$; sexta, la de Júpiter $=2$, y séptima, la de Saturno $=\hbar$ (Apiano K2r; trat. I, cap. XXXII). Por antonomasia, la conjunción magna es la de los dos planetas extremos, que son también los más grandes y lentos del sistema solar (tal y como se lo conocía hasta el descubrimiento de Urano en 1781). Según explicaba Pierre d'Ailly: "Coniunctio maxima est quando coniunguntur tres planete superiores, scilicet, Saturnus, Iupiter et Mars. Coniunctio maior est Saturni cum Iove. Minor, Iovis cum Marte. Media, Saturni cum Marte" (Concordantice b1r; trat. I, cap. xiii).

20 Se refiere a la unidad ibérica, poniendo una sola silla real o trono en todo el territorio, hecha de una rama cortada de laurel (símbolo del imperio), volviendo a la prístina integridad territorial visigótica ("primer grandeza") por la anexión de Portugal en 1580. 
Las conjunciones son uno de los cinco aspectos astrológicos principales, los cuales permiten referirse a las posiciones relativas que los astros guardan entre sí respecto de un tercer punto de observación (en este caso, la Tierra). Tal como refleja la Figura 3, los aspectos corresponden a determinadas distancias angulares entre los planetas, las cuales son divisores enteros de $360^{\circ}$ y tiene un margen de tolerancia, actualmente llamado orbe. Cuando un aspecto concuerda con su medida exacta, se denomina partil; cuando se halla

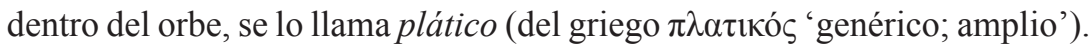

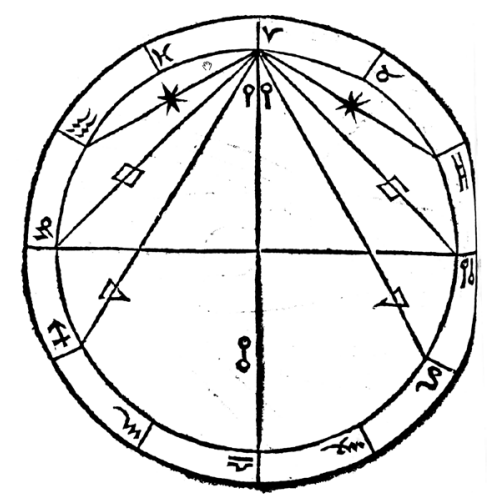

FigURA 3. Esquema de los aspectos: oposición $\left(0^{\circ}, \Varangle 180^{\circ}\right)$, trígono $\left(\triangle, \Varangle 120^{\circ}\right)$, cuadratura $\left(\square, \Varangle 90^{\circ}\right)$, sextil $\left(*, \Varangle 60^{\circ}\right)$ y conjunción $\left(\sigma, \Varangle 0^{\circ}\right)$, según Peuerbach (26v); damos los símbolos y ángulos entre paréntesis.

Es decir, de entre las cinco posiciones relativas principales que pueden tener los planetas entre sí, conocidas como aspectos, la conjunción consiste en la agrupación de dos o más astros respecto del punto de observación establecido, cuando se hallan en la misma longitud celeste. Dicho en términos más precisos, se produce una conjunción planetaria cuando la distancia angular entre dos (o más) planetas es de cero grados $\left(\Varangle 0^{\circ}\right)$, medidos sobre la eclíptica. En cuanto al orbe, los astrólogos actuales le atribuyen a la conjunción un orbe único de $8^{\circ}$ (Leo 210 ) o de $10^{\circ}$ (Fuzeau-Braesch 16, García Ferrández 77). Sin embargo, entre los tratadistas del período 
que informan de este valor (que no son muchos), se suele cifrar ese orbe en nueve grados ${ }^{21}$, por lo que dos planetas estarían en conjunción siempre que su distancia angular se situase en el intervalo $0^{\circ} \leq \gamma \leq 9^{\circ 22}$.

No obstante, como se desprende del silencio de la mayoría de los autores astrológicos de la época, el aspecto se restringía normalmente al exacto o partil. Así se deduce de la precisión con que se refieren a los momentos en que se produce esta situación, así como de la siguiente observación de Peuerbach: "Coniunctio media planetarum fit quando lineæ mediorum motum eorum secundum longitudinem Zodiaci coniunguntur. Vera autem, quando lineæ verorum motuum sic conueniunt. [...] Similiter de oppositione media et vera dicendum. Et attenduntur hæ in eisdem signo, gradu et minuto" (27r).

\section{EL CONJUNCIONISMO}

Para entender el alcance de la alusión a la conjunción magna en el precitado pasaje de El Bernardo (en lo relativo tanto a la fecha de nacimiento de Balbuena como a su autoconciencia poética), es preciso añadir a la información astronómica previa una explicación sobre el conjuncionismo o doctrina de la especial relevancia histórica de las conjunciones magnas, que se originó en la Persia sasánida, como resultado de la hibridación de doctrinas indoiranias y helenísticas. Llegó a Europa de la mano de dos astrólogos que vivieron a caballo de los siglos VIII y IX: el judío Māšāa allāh ibn Atarī y el persa Abū Ma šar Ğa far ibn Muḥammad al-Balhī conocidos, respectivamente, en las fuentes occidentales, como Messahala (o Messahalach) y Albumasar, cuyos correspondientes tratados De ratione circuli et stellarum y De magnis coniunctionibus se divulgaron en sendas traducciones latinas hechas por

21 Lepoldo de Austria (22r; trat. I, pte. II, § [3]), Apiano (F3v; pte. I, enunc. XIX), Brunfels, De deffinitionibus (a5r). D'Ailly se conforma con que coincidan en el mismo signo (Elucidarium flv; cap. XIII), lo que equivale, en la práctica, a un orbe de casi $30^{\circ}$, mientras que Cardano parece establecer uno de $2^{\circ}$ (De iudiciis geniturarum 63v; cap. VII = Opera omnia 5: 444). Naboth, por su parte, lo cifra en "vi gradus vel infra" (316). Núñez de Zamora, para el caso de Júpiter y Saturno, admite como intervalo "un año casi entero", lo que supone un orbe de unos $10^{\circ}$ (24; cap. III).

22 Expresado en términos más estrictos, dada una distancia angular $\gamma$ y estando su orbe dentro del intervalo cerrado $o=\left[0^{\circ}, 9^{\circ}\right.$, aquella pertenece al conjunto $\mathbb{C}$ de las conjunciones, si cumple la condición de hallarse dentro de dicho intervalo: $\left\{\gamma \in \mathbb{C} \mid 0^{\circ} \leq \gamma \leq 9^{\circ}\right\}$. 
Juan de Sevilla y su entorno en el siglo XII y sus respectivas ediciones príncipe vieron la luz en Basilea en 1533 y en Augsburgo en 1489 (Samsó 711, Yamamoto y Burnett 2: XI-XXIX).

Esta doctrina se basa en dos principios; uno es la importancia de las conjunciones magnas, expuesta ya por Messahala, según la cual señalan grandes cambios, como el surgimiento, mutación o caída de sectas religiosas y profetas, o bien de reinos y soberanos. El otro es el principio de recurrencia, señalado por Albumasar, de acuerdo con cuyos cálculos la conjunción de Saturno y Júpiter se produce cada veintena de años en un signo zodiacal de la misma triplicidad (Figura 4), es decir, los que distan entre sí $60^{\circ}$ de la eclíptica ${ }^{23}$, de modo que cada sesenta años ambos planetas vuelven a encontrarse en el mismo signo, pero con un desfase de siete u ocho grados, por lo cual, al cabo de cuatro ciclos de conjunciones, que suman doce y ocupan 240 años, la decimotercera conjunción se produce en un signo distinto y, por lo tanto, en una nueva triplicidad (Figura 5).

$$
\begin{aligned}
& \text { Fuego, } \left.\left\{\begin{array}{l}
\text { Aries. } \\
\text { Leo. } \\
\text { Sagitario. }
\end{array}\right\} \begin{array}{l}
\text { Calientes y } \\
\text { fečos. }
\end{array}\right\} \text { Colericos. } \\
& \text { Ayre. }\left\{\begin{array}{l}
\text { Geminis. } \\
\text { Libra. } \\
\text { Aquario- }
\end{array}\right\} \begin{array}{l}
\text { Calienresyz } \\
\text { humedos. }
\end{array} \text { Sanguineos. } \\
& \text { Agua. } \left.\left\{\begin{array}{l}
\text { Cancer. } \\
\text { Scorpio. } \\
\text { Pifcis. }
\end{array}\right\} \begin{array}{l}
\text { Friosyhu } \\
\text { inedos. }
\end{array}\right\} \text { Flegmaticos. } \\
& \text { Tierra. } \left.\left\{\begin{array}{l}
\text { Tauro. } \\
\text { Virgen. } \\
\text { Eapricornio. }
\end{array}\right\} \begin{array}{l}
\text { Frios y } \\
\text { fecos. }
\end{array}\right\} \text { Melaricolicos. }
\end{aligned}
$$

Figura 4. Triplicidades y cualidades de los signos zodiacales (según Tornamira 469). 


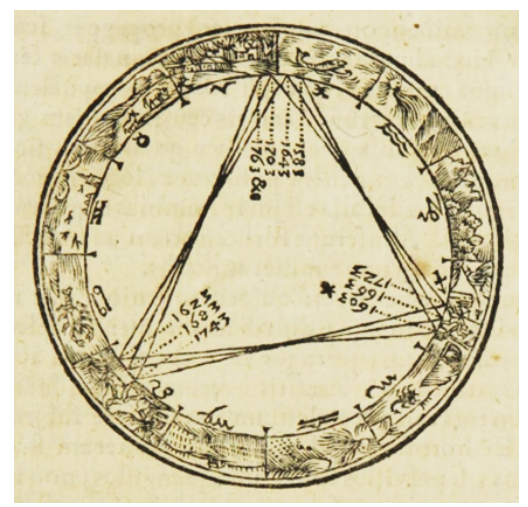

Figura 5. Paso de la conjunción magna desde la triplicidad ácuea (Piscis) a la ígnea (Aries) entre 1583 y 1763, según Kepler (25; cap. vI). La conjunción magna media de 1603 está marcada con un asterisco.

Al cabo de cuatro ciclos de cambio de signo, que suman cuarenta y ocho conjunciones y 960 años, la conjunción vuelve a producirse en el mismo grado del signo original $\left(0^{\circ}\right.$ de Aries), cerrando el ciclo máximo, llamado gran año o año mundial ${ }^{24}$. De este modo, en un año mundial se producirían un total de 48 conjunciones magnas, de entre las cuales la más importante sería la inicial de la triplicidad ígnea (en $0^{\circ}$ de Aries), recibiendo el nombre de conjunción magna máxima, después las 3 iniciales de cada una de las otras triplicidades, conjunciones magnas medias, y, por último, las 44 restantes, conjunciones magnas menores ${ }^{25}$. Las cifras dadas por Albumasar fueron posteriormente corregidas mediante las más exactas tablas alfonsíes, ofreciendo los sucesivos tratadistas diversos valores, que quedan recogidos en la siguiente tabla (donde se han redondeado a horas), siendo los de Reinhold, en sus nuevas tablas pruténicas, los corroborados por la moderna astrometría:

$24 \quad$ Una explicación breve y precisa puede verse en North (341). Ofrecen sendas síntesis del desarrollo y evolución del conjuncionismo Geneva (118-140) y Federici Vescovini, en ambos casos con una exposición técnica insuficiente (para lo cual, véase Etz).

25 La terminología sistematizada que ofrecemos se basa particularmente en Pierre d'Ailly (Elucidarium f5r; cap. XXv, y Concordantice b7r -v; trat. II, cap. I) y en Cardano (Aphorismi 211v-212r; segm. I, §§ 64-68 = Opera omnia 5: 32-33). 


\begin{tabular}{|l|l|l|}
\hline Autor & $\begin{array}{l}\text { Período entre } \\
\text { conjunciones } \\
\text { magnas menores }\end{array}$ & $\begin{array}{l}\text { Período entre conjunciones } \\
\text { magnas máximas (gran año) }\end{array}$ \\
\hline Albumasar (preciso) $^{1}$ & $19 \mathrm{a}, 314 \mathrm{~d}, 14 \mathrm{~h}$ & $996 \mathrm{a}[=993 \mathrm{a}, 34 \mathrm{~d}, 23.68 \mathrm{~h}]$ \\
\hline Albumasar (redondeado) $^{2}$ & $20 \mathrm{a}$ & $960 \mathrm{a}$ \\
\hline D'Ailly $^{3}$ & $19 \mathrm{a}, 313 \mathrm{~d}$ & $953 \mathrm{a}, 91 \mathrm{~d}$ \\
\hline Cardano $^{4}$ & $19 \mathrm{a}, 315 \mathrm{~d}, 19 \mathrm{~h}$ & $794 \mathrm{a}, 214 \mathrm{~d}$. \\
\hline Reinhold $^{5}$ & $19 \mathrm{a}, 314 \mathrm{~d}, 2.75 \mathrm{~h}$ & - \\
\hline
\end{tabular}

NOTAS A LA TABLA

Albumasar (9-10; I, i, 16). Para la corrección entre corchetes, véase Yamamoto y Burnett (1: 13).

2 Albumasar (8-9; I, i, 12 y 15). Estas cifras fueron las comúnmente aceptadas durante la Baja Edad Media, cf. Alcabitius (53r; IV, [1]); Leopoldo de Austria (27v; IV, iv, 1); Juan de Sajonia (43v) o Pierre d'Ailly (Concordantice b1r-b2r y b7v; conc. I, caps. xiii-xv y conc. II, cap. i).

3 D'Ailly (Elucidarium $f 6 v$; cap. xxvi); previamente se había atenido a la versión simplificada de Albumasar (véase la nota precedentE).

4 Cardano (Aphorismi 211v-212r; segm. I, $\S \S 65-66=$ Opera omnia 5: 32). Sus cómputos fueron seguidos por autores como Naboth (354), Tornamira (162-163; cap. liii), a quien citamos a continuación, o Núñez de Zamora (20 y 28, cAP. III).

5 Reinhold (47r; prceceptum xxxvii). Este autor publicó en el año 1551 sus Tabulce Prutenicce, cuyos cálculos corrigieron en buena medida los de las tablas alfonsíes, basándose tanto en observaciones más precisas como en el modelo heliocéntrico expuesto en el De revolutionibus orbium coelestium de Copérnico. Sus cálculos fueron seguidos por Riccioli (1: 675; lib. VII, sec. V, cap. ix, § 12). Ambas tablas astronómicas quedaron superadas en 1627 con la publicación de las rudolfinas, comenzadas por Brahe y completadas por Kepler.

Como puede apreciarse, la principal diferencia no radica, realmente, en el cómputo del intervalo entre conjunciones, sino en el del gran año, cuya enorme diferencia se debe, en realidad, a un cambio del punto de referencia: las cifras ofrecidas por los astrólogos medievales están calculadas, al parecer, estableciendo el punto de retorno respecto de las estrellas fijas, lo que ocasiona un ciclo más largo (exagerado, además, por defectos de cálculo), mientras que las dadas por los astrólogos renacentistas lo establecen respecto al punto vernal, lo que reduce considerablemente el período, pasando de ser de casi mil años a poco menos de ochocientos ${ }^{26}$.

26 Según los valores hoy establecidos, el período entre dos conjunciones magnas máximas respecto de las estrellas fijas dura, en promedio, 893 a, 255 d, 16.2 h, y respecto del 
Esta importante reducción afectó considerablemente a las explicaciones históricas basadas en los ciclos de conjunciones magnas máximas, en particular, respecto de la cronología arrojada por la historia sagrada ${ }^{27}$. Así, Brahe, tomando como punto de referencia la aparición de la supernova SN 1572 o Nova Tycho, consideró la historia humana secuenciada en siete ciclos de conjunciones magnas (aunque la mayoría no máximas en realidad), en períodos de unos 815 años. De este modo lo plantea en sus Astronomice instauratce progymnasmata, obra que tal vez conociera Balbuena:

Et si septima hæc est trigonorum in integrum ab Orbe condito restitutio, quemadmodum communiter recepta ætatis Mundi numeratio admittit, ita ut prima in Enocho, secunda in Noâ et Diluvio, tertia in Mose et liberatione populi a servitute Ægyptiaca, quarta in regibus Israëliticis, quinta in Christo et monarchiæ Romanæ apice, sexta in Carolo Magno et imperii ad Germanos translatione absoluta sit, utique septima hæc Sabbatissimi quandam occultam rationem obtinet, et præ cæteris peculiare et magni momenti quid denunciat. Ubi animadversione dignum censeo, quod veluti illæ restitutiones trigonicæ, quæ impari numero exhibitæ sunt, velut prima, tertia et quinta, salutares Mundo fuerunt. Sic et hanc septimam numero imparei præcipue gaudentem, magni cuiusdam boni et felicioris status esse prænunciam (805-806).

Aunque Brahe no lo explicita, la secuencia sería la siguiente (como puede apreciarse en la Figura 5): 1] 1572: aparición de la Nova Tycho en 1572, en Casiopea $\left.^{28}, 2\right]$ 1583: ultima conjunción magna del trígono ácueo, en Piscis ${ }^{29}$,

nodo equinoccial vernal, 794 a, 146 d y 2.4 h. Para todo lo relativo a esta cuestión, véase Etz (176-177).

27 Esta tradición, entre astrólogos cristianos, fue iniciada por Pedro Abano en su Conciliator, que dividió la historia de la salvación en siete eras en función de las conjunciones magnas de Albumasar (Geneva 130); y desarrollada a partir de entonces por autores como Roger Bacon o Pierre d'Ailly, quienes, a su vez, recogían la división de la historia sagrada en seis siglos o edades que hiciera san Isidoro de Sevilla, Etymologice, V, XXXVIII, 5.

28 Casiopea (cuya ascensión recta se sitúa entre 22 h $57.08 \mathrm{~m}$ y 3 h $41.23 \mathrm{~m}$ ) se halla aproximadamente en la misma longitud ecuatorial que Piscis (entre 22 h 51.29 m y 2 h 6.66 $\mathrm{m})$.

$29 \quad$ "Si itaque ex eius coniunctionis loco, qui incidit in 21 grad. $)$ [ $=$ Piscium] ad situm novæ stellæ per ascensiones rectas [...] instituerimus, perueniet ad punctum quod stella in æquatore designabat, novem proxime annis a conjunctionis illus ponderosissima tempore numerandis, cumque hæc anno Christi 1583, in fine Aprilis, peracta sit” (Brahe 804). La 
y 3] 1603: primera conjunción magna del trígono ígneo, en Sagitario ${ }^{30}$. Como se ha visto, el cambio de triplicidad de 1603 era interpretado por Brahe favorablemente, mientras que los astrólogos tradicionales seguían entendiéndolo de modo catastrofista:

de aquí se pasará, por ser la última conjunction de las que se hacen en signos de natura de agua, a hacerse las dichas conjunctiones a la triplicidad de fuego, y la primera será en los once grados de Sagitario, el último de deciembre, año 1603, la cual será la que los astrólogos amenazan con grandes calamidades y destruiciones de reinos, sacándolo por las experiencias que tienen de otras semejantes, como fue en tiempo que se perdió España, y de Carlo Magno (Tornamira 164, cap. LIII) ${ }^{31}$.

Por su parte, Naboth, amparándose en Ptolomeo, negaba que las conjunciones magnas tuviesen un sentido especial: "Tempora vero magnarum euentuum non a Saturno \& Iouis coniunctionibus, sed potiùs a deliquiis esse supputanda [...] Præterea Ptolemæus in hoc negotio trium superiorum non insitam vim, sed a deliquiis desumptam, atque ad effectum productam considerat" (357). Otros autores, en cambio, consideraban, como Brahe, que algunas de las conjunciones venideras constituían buenos pronósticos. Así pensaba Campanella, el cual, consideraba en su De monarchia hispanica discursus que la próxima conjunción magna en Sagitario, identificado con Hispania desde la Antigüedad ${ }^{32}$, produciría el advenimiento de la monarquía hispánica universal en íntima unión con el papado romano: "Verum ecclipsis

conjunción tuvo lugar el 3 de mayo, a $23 \mathrm{~h} 25 \mathrm{~m} 37 \mathrm{~s}$ de ascensión recta $(\alpha)$, lo que equivale a $20^{\circ} \mathrm{Psc} 10^{\prime} 48^{\prime \prime}$ en longitud eclíptica $(\lambda)$. Todos los datos astronómicos se toman de Ofek, cuyas coordenadas ecuatoriales se han transformado en eclípticas mediante el conversor de Switzer, mientras que las cartas astrales se han calculado y trazado con el programa Morinus 6.2.

30 Compárese la Figura 5. La conjunción magna media de 1603 tuvo lugar el 18 de diciembre, $\alpha=16$ h $26 \mathrm{~m} 34 \mathrm{~s}, \lambda=8^{\circ}$ Sgr 18' 2".

$31 \quad$ Núñez de Zamora, denuncia que "algunos se hayan arrojado a decir que con esta máxima conjunción se ha de acabar el mundo" (21, cap. III), lo que concuerda con lo previsto por D'Ailly para la octava conjunción, que había fechado en 1693 vel circiter y relacionaba con la venida del Anticristo (Concordantice d7v-d8r; conc. I, caps. LX-LXI).

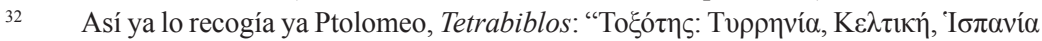

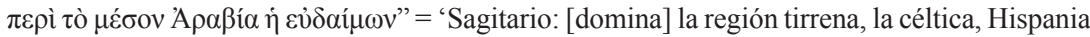
y, en torno al medio, Arabia Feliz’ (158; lib. II, cap. III, § 75; cf. además $\S 63$ y 66). La doble mención de Hispania y de parte de Arabia (que justifica la interpretación de Balbuena) 
et coniunctio magna in Sagittario, signo scilicet Hispaniæ, plura secreta, quæ et ipsa edisseram, revelabunt" (33; cap. IV) ${ }^{33}$.

Se trata de una interpretación común a gran número de tratados astrológicos del siglo XVII, como el de Antonio Núñez de Zamora, para quien anunciaba "diminución notable en la secta de Mahoma y, por averse hecho en la décima [casa astrológica], que el imperio [de los turcos], que en la triplicidad contraria tuvo origen, caerá y cesará durante esta máxima conjunción" (19, cap. iii). En la misma línea se sitúan Antonio de Nájera, Francisco Navarro, Francisco Temudo, Esteban Casellas y Cristóbal de Montalvo ${ }^{34}$, los cuales consideraban que tras un periodo de preponderancia islámica que había comenzado con una conjunción magna en el signo ácueo de Escorpión, la nueva conjunción magna media en Sagitario, con la entrada en la triplicidad ígnea, traería un periodo de auge del catolicismo y de la monarquía hispánica.

\section{BALBUENA Y EL CONJUNCIONISMO}

La alusión a la conjunción magna por parte de Balbuena en El Bernardo solo se hace un vago eco de estos planteamientos, cuando dice que aquella "a España entero volverá el tesoro / que su infeliz concurso le deshizo" (XVII, 87, 2 y 5-6), esto es, que la misma conjunción de Saturno y Júpiter que provocó la pérdida de España será su restauradora. Aquella, no es, sin embargo, la nueva conjunción magna media que corresponde al cambio de triplicidad en 1603 (véase la Figura 5), sino que, como ahora veremos, se trata de una conjunción magna menor ocurrida en Cáncer, coincidente con el nacimiento del propio Balbuena. No se trata, pues, de una de las conjunciones más significativas, desde el punto de vista de los grandes cambios atribuidos a las mismas, por lo que posiblemente el sentido de la expresión sea más laxo y responda a una oposición genérica entre la España abatida por la ocupación musulmana y la exaltada en pleno apogeo imperial. Esto concuerda, en cualquier caso,

aparece también en Albumasar: "Sagittarium habet ex regionibus [...] Hispaniam et Aliemen [= Yemen]" (142; trat. IV, apénd. I, § 11).

33 Sobre el conjuncionismo de Campanella, experto astrólogo, véase Woody (125).

34 Sobre estos y otros astrólogos españoles que apelaron al conjuncionismo para presentar una explicación científica de la historia, véanse Lanuza Navarro "La astrología..." y "Astrological Literature...". 
con el nacionalismo como fundamento ideológico de El Bernardo (sobre el cual, véase Friedlein 312-321), que se expresa también en clave astrológica:

Que la estrella de España en este mundo

en todo es superiora de otra estrella;

así los cielos en saber profundo

para más bien lo dispusieron de ella (XIX, 4, 1-4).

Existe, no obstante, un vínculo entre esta conjunción efectuada en Cáncer y el signo de Sagitario, que refuerza la conexión implícitamente realizada por Balbuena:

Anno Christi Dei 1563 celebrabitur coniunctio magna Iovis et Saturni, ac iuxta Alphonsinorum quidem calculum diebus Septembris completis 26 , horis circiter 6 post meridiem, in parte 4 , scrup. $8,1 .^{a}$ Leonis; iuxta calculum Prutenicum vero diebus Augusti completis 25, hora circiter decima post meridiem, in parte 29 Cancri. Porro pars horoscopans in revolutione annua seu, ut vocant, pars ad momentum temporis quo Sol primum punctum Arietis in illo anno attinget, ascendens erit iuxta ipsorum calculum pars 16 Sagittarii. Hac de causa, Sagittarius magnæ illius coniunctionis ascendens ipsis vocabitur (Naboth 357-58).

Con todo, Balbuena se ciñe básicamente al planteamiento original de Albumasar, es decir, "qualiter aspicitur ex parte coniunctionum apparitio prophetarum et eorum qui principantur successuumque eorum" $(3 ; \mathrm{I}, 1)$, sin un marcado influjo de las reelaboraciones judeocristianas sobre las diversas edades del mundo. Así, en el pasaje citado al principio de estas páginas, se centraba en señalar la situación "al pueblo moro / favorable" que supone la conjunción magna "en el frío Sagitario" ${ }^{35}$, en referencia a su usurpación o "cetro advenedizo" de la monarquía hispánica (87, 3-4). Una idea semejante se aprecia en una mención anterior hecha en El Bernardo por boca del rey

35 Sagitario es cálido y seco (véase la Figura 4), por lo que parece errar Balbuena al calificarlo de frío; pero esta adjetivación no depende de las cualidades intrínsecas del signo, sino de las extrínsecas de tipo estacional: "Es Sagitario signo común, porque cuando entra el Sol en él, que es a XXII de Noviembre, participa del tiempo del otoño y del invierno" (Tornamira 57; cap. XIX). 
Rodrigo. El monarca que perdiera a España, en un episodio que reelabora la leyenda medieval sobre su penitencia redentora, predice así su propia muerte:

Toda esta magna conjunción que, junta,

favorece a los árabes furores, y en Sagitario y su primera punta

harán los dos planetas superiores, el fin y el punto de mi muerte apunta.

Hasta ella sola llegan los mayores términos del periodo de mi vida, si antes no abrevia el cielo la partida (XII, 166).

Dado que se refiere al fallecimiento de don Rodrigo, cabría pensar que se trata de la misma conjunción magna aludida en XVII, 86-87, que anunciaría a un mismo tiempo la caída del reino visigótico y la muerte de su último rey. Sin embargo, la que pronostica este suceso se produce tras un siglo de penitencia, "cien años de continuo llanto" (XII, 165, 7) ${ }^{36}$. No se trata, pues, de la misma conjunción magna ocurrida en Sagitario, sino de la siguiente, producida en el mismo signo, que tendría que haber ocurrido, no cien, sino sesenta años después, según el cómputo simplificado de Albumasar ${ }^{37}$.

Sea como fuere, la conjunción aludida en el canto XVII, pasada ayer, es decir, antes del inicio de las hazañas de Bernardo, ha de identificarse con la que los tratadistas del Siglo de Oro correlacionaban con la invasión musulmana, como ya se ha visto en el precitado pasaje de Tornamira y corrobora León Pinelo: "Año 710. Conjunción magna anunció la pérdida de España. A 22 de enero fue la conjunción magna de los planetas superiores, Saturno y Júpiter, que dicen anunció la pérdida de España y entrada de los moros en ella"38. Esta se produjo realmente el 5 de febrero, en los $32^{\circ} 16^{\prime}$ de Piscis.

36 Un poco antes, don Rodrigo había señalado, tras describir su modus vivendi en su retiro eremítico, que "De esta suerte he corrido el curso entero / de un siglo" (XII, 162, 1-2).

37 Según el de D’Ailly, serían 59 años y 208 días; según el de Cardano, 59 años y 215 días, y según el de Reinhold, 59 años y 222 días (en años julianos, 59 a 118 d 16 h).

38 León Pinelo (22v); en la edición de Fernández Martín se estampa la errata "Año 720". Se ha de notar que el analista no sitúa ese año la invasión musulmana, pues fecha la "primera entrada de los árabes en España" en 712 (22r); la segunda, en 713 (22v) y la "tercera entrada de los árabes y pérdida de España” en 714 (23r), en lo que concuerda con Garibay, 
En cuanto a la muerte de don Rodrigo, habría que situarla, según lo dicho, en torno a 810 , datación que podría relacionarse con la translatio imperii ad Germanos que comenta Brahe en el pasaje antes citado, ya que la coronación imperial de Carlomagno tuvo lugar el 25 de diciembre de 800, algo que plantea explícitamente Núñez de Zamora al tratar de la conjunción magna ocurrida en "el año de 809 en 6 [grados] de Sagitario" (33; cap. iii) $)^{39}$. Si se cuenta 710 como primer año (ya que la conjunción magna sucedió a principios del mismo), entonces 809 sería el centésimo. Además, la identificación con esta última conjunción, producida en los primeros grados de Sagitario, explica el verso XII, 166, 3, por metonimia de la constelación con el signo homónimo ( $c f$. Montaner, "Rufo astrólogo" 185), pues la primera punta de la flecha corresponde a Tau Sagittarii, su primera estrella.

Ahora bien, según Balbuena, la conjunción "favorece a los árabes furores", por lo que, aunque la fecha implícita podría ser la indicada, su correlato histórico no parece ser otro que la batalla de Roncesvalles. Aunque fechada por la analística altomedieval en 778, según Garibay, "Esta batalla muy decantada en la nación Española, y no menos celebrada en las historias de España y Francia, y aun de otras naciones, pasó en el año del nascimiento de nuestro Señor de ochocientos y nueve, según las historias de España" (1: 425; lib. IX, cap. xv). De este modo, se unen, a través de la muerte de don Rodrigo, el desastre de 710 (711) en Guadalete con el de 809 en Roncesvalles, incluso si, en la versión de Balbuena, que sigue la tradición historiográfica de las crónicas alfonsíes (Zulaica 1: 237), esta batalla contra los franceses la libran conjuntamente "españoles" y "moros", siendo su gran protagonista el propio Bernardo.

Finalmente, además de estas referencias históricas, la conjunción magna aparece como un importante marcador astrológico respecto del nacimiento del propio Balbuena. Aunque el conjuncionismo es, como se ha visto, una doctrina de la astrología mundana (o sociohistórica), también hay antecedentes de su aplicación a la más habitual astrología genetlíaca (o individual). Posiblemente, este planteamiento se halle implícito ya en la referencia de Dante a su nacimiento bajo el signo de Géminis, al que el poeta toscano

que sitúa la invasión en 713 y data la batalla de Guadalete el 4 o 7 de septiembre de 714 (1: 374-376; lib. VIII, cap. XLVIII).

39 Esta conjunción magna media, con cambio de triplicidad de ácuea a ígnea, se produjo el 5 de octubre de 809 , en $\operatorname{los} 3^{\circ} 20^{\prime}$ de Sagitario. 
declara deber todo su ingenio, en el Paradiso, XXII, 112-17. Dado el interés de Dante en las "stelle propinque" (Purg. XXIII, 41), es más que probable que, según explica Woody (1977), se encierre aquí también una alusión a la conjunción magna de 1265 , que tuvo lugar precisamente en $9^{\circ} 40^{\prime}$ de Géminis.

Ya en el tránsito de los siglos XIII al XIV el filósofo flamenco Enrique Bateno de Malinas (Hendrik Bate van Mechelen, ca.1246-1310) destaca este elemento en su autobiografía Nativitas: "Iterum est et Libra signum coniunctionis presentis, que scilicet erat in anno nativitatis huius quam pre manibus habemus" (166; 11. 981-985) ${ }^{40}$ y no sin causa, habida cuenta de la significación deducible del evento: "coniunctio Iovis cum Saturno significat magnum sapientem" (161; 11. 853-854, cf. también 222; 11. 2407-9).

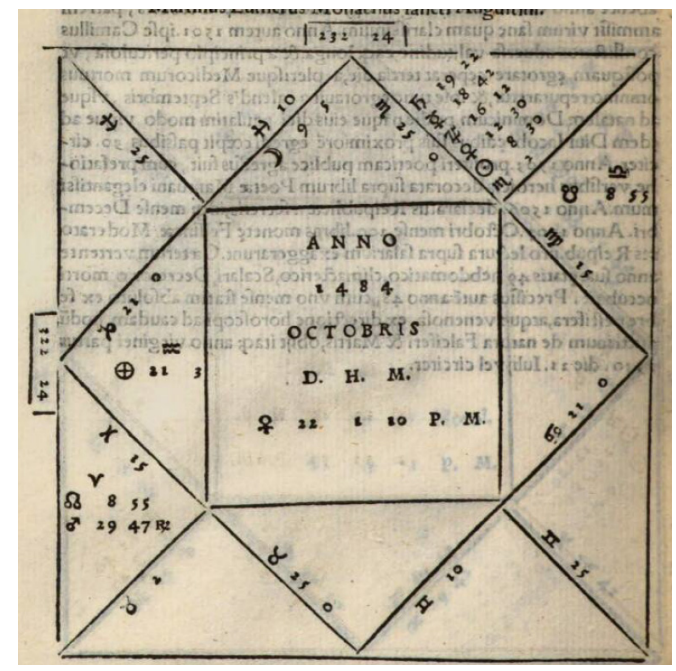

Figura 6. Carta natal de Lutero, según el Tractatus astrologicus (1552) de Gaurico $(69 \mathrm{v})$

El caso más sonado, a este respecto, fue el de la carta natal de Martín Lutero, cuyo nacimiento había establecido Gaurico en su Tractatus astrologicus,

40 Esta conjunción tuvo lugar el 21 de septiembre de 1246 en los $19^{\circ}$ Libra, no en los $21^{\circ}$, como señalaron los editores de la Nativitas (101). 
mediante la técnica astrológica conocida como rectificación, el 22 de octubre de 1484, a las 13 h 10 m, de modo que su carta natal muestra la conjunción en Escorpio de Saturno, Júpiter, Venus, Mercurio y el Sol (Figura 6). Su comentario incide en este hecho, pero no presta ninguna atención a la conjunción magna $(69 \mathrm{v})$, pese a que hubiera reforzado esta interpretación. Cardano rechazó esta carta, fechando la suya en " 1483 , die 22 octobris, hor. 10 post meridiem", pese a lo cual sí hace una referencia prospectiva a la conjunción magna del año siguiente ("De exemplis centum geniturarum" $114 \mathrm{v}-115 \mathrm{r} ; \S \mathrm{XI}=$ Opera omnia 5: 465). Curiosamente, los apologetas protestantes aceptaron la propuesta de Gaurico, limitándose a "rectificar" la hora, para ofrecer un resultado más positivo:

Philipp Melanchthon, Johann Carion, the Wittenburg mathematician Erasmus Reinhold, and the doctor Johann Pfeyl - were also convinced of Gaurico's date, October 22nd 1484 - but not of the time of birth. Considering Luther to be much more philanthropic and positive, Melanchthon and Carion suspected he had been born at 9:00 p.m., while Pfeyl surmised 3:22 p.m. In both cases, Luther comes off better $(\text { Schoener 62) })^{41}$.

\section{EL NACIMIENTO DE BERNARDO DE BALBUENA: ENTRE LA DOCUMENTACIÓN, LA ASTROLOGÍA Y LA ONOMÁSTICA}

A lo largo de las anteriores secciones hemos ofrecido un sumario de la datación documental del nacimiento de Bernardo de Balbuena, así como una explicación de la doctrina astrológica de las conjunciones magnas, de su difusión y de su utilización por nuestro poeta. Resta, en último lugar, volver sobre los mencionados versos de El Bernardo (XVII, 86-87) para ofrecer su interpretación en relación, no con la narración poética, sino con su autor. La indicación de Balbuena sobre la coincidencia de su natalicio con este fenómeno astrológico tiene dos importantes consecuencias. Por un lado,

41 Posteriormente, Melanchton, tras consultar a la madre de Lutero, tras la muerte de este, fijó la fecha en el 10 de noviembre de 1484, al filo de la medianoche, pero mantuvo el año, aunque finalmente se inclinó por 1483, según información recabada de la familia de su hermano Jakob Luther (Brecht 1, Schoener 62). Sobre el papel de Gaurico, $c f$. además Geneva (134). 
permite precisar la fecha de su nacimiento que, hasta ahora, solo se había podido establecer conjeturalmente en el intervalo recogido en la Figura 2; por otro, otorga especial significación al suceso, insertándolo en una cadena histórica y dotándolo de relevancia personal.

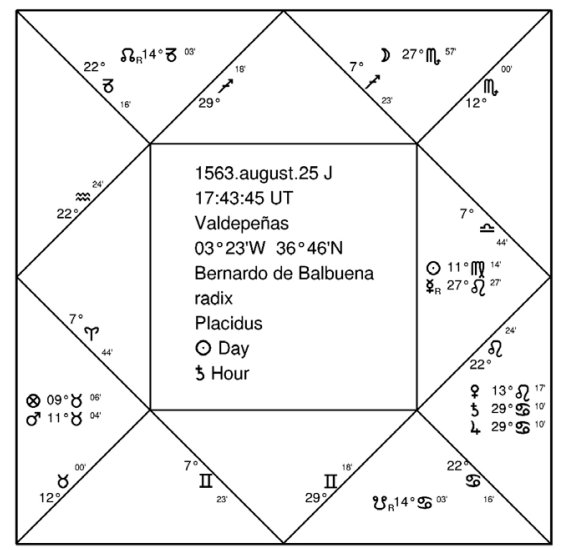

FiguRA 7. Carta astral correspondiente a la conjunción magna de 1563 en las coordenadas de Valdepeñas.

Comenzando por la cuestión cronológica, la conjunción magna de 1563 se produjo el 25 de agosto, a las $17 \mathrm{~h} 43 \mathrm{~m} 45 \mathrm{~s}$ UTC con una ascensión recta de $\alpha=8$ h $5 \mathrm{~m} 36 \mathrm{~s}$ y una longitud eclíptica de $\lambda=119^{\circ} 10^{\prime} 6^{\prime \prime}$, que corresponde a $29^{\circ} 10^{\prime}$ de Cáncer (Figura 7). Esta información era fácilmente accesible para Balbuena, en fuentes como la Enarratio (1560) de Naboth, citada arriba, que situaba la conjunción a las $22 \mathrm{~h}$ del 25 de agosto en los $29^{\circ}$ de Cáncer, o bien la ya mencionada Chronographia (1585) de Tornamira, quien la sitúa "a XXIIII de agosto, en XXIX grados de Cáncer" (164; cap. LIII). Por su parte, Stade la fechaba igualmente el 24 de agosto, en los $28^{\circ}$ de Cáncer (L14r), aunque alcanzaría su máximo al día siguiente, en los $29^{\circ}$, con $\gamma=1$ ' (L13v). Más tarde, Riccioli la situaría "Augusti 26, hor. 10, in Cancri gr. 29" (1: 676; lib. VII, sec. V, cap. x, § 4). En principio, la fecha exacta de la misma ofrece el centro de un intervalo que, a tenor de lo visto arriba, variará según el orbe aplicado. Teniendo en cuenta los empleados por la astrología de la Edad Moderna temprana, las posibilidades son las recogidas en la siguiente tabla: 


\begin{tabular}{|l|l|l|l|}
\hline Aspecto & Orbe & Fecha inicial & Fecha final \\
\hline \multirow{4}{*}{ Plático } & $10^{\circ}$ & $14 / \mathrm{V} / 1563$ & $14 / \mathrm{VII} / 1564$ \\
\cline { 2 - 4 } & $9^{\circ}$ & $16 / \mathrm{V} / 1563$ & $9 / \mathrm{VII} / 1564$ \\
\cline { 2 - 4 } & $6^{\circ}$ & $12 / \mathrm{VI} / 1563$ & $5 / \mathrm{VII} / 1564$ \\
\cline { 2 - 4 } & $2^{\circ}$ & $1 / \mathrm{VIII} / 1563$ & $27 / \mathrm{II} / 1564$ \\
\hline Partil & $0^{\circ}$ & $25 / \mathrm{VIII} / 1563$ & \\
\hline
\end{tabular}

Teniendo en cuenta que el orbe más comúnmente usado en la época era el de $9^{\circ}$, las fechas extremas se situarían entre el 16 de mayo de 1563 y el 9 de julio del año siguiente, si bien la elevada probabilidad de que Balbuena esté siguiendo a Naboth, haría preferible el orbe de $6^{\circ}$ consignado por este autor (véase la nota 20), con lo que el período iría desde el 12 de julio de 1563 al 27 de febrero del siguiente año. Si se realiza la intersección de este intervalo con el arrojado por las referencias documentales, que va del 9 de abril de 1562 al 7 de noviembre de 1563 (Figura 2), el lapso queda acotado entre el 12 de julio y el 7 de noviembre de 1563. Así, contra la tendencia de la mayor parte de la crítica, que, en un consenso de facto, sitúa ca. 1562 el nacimiento de Balbuena, podemos afirmar que este tuvo lugar en el año 1563 , según corrobora la concordancia entre lo señalado por el propio autor en la información de 1584 y en El Bernardo.

Ahora bien, dada la preferencia coetánea por el aspecto partil y siendo que el mismo Naboth subraya que "cum gradus eorum [sc. planetarum] fuerint æquales, perficitur coniunctio eorum" (316), es de suponer que Balbuena se refería a una fecha bastante precisa, la cual, aunque seguramente no coincidiría de modo exacto con la propia conjunción magna, se situaría en sus cercanías, por lo que puede aventurarse una datación en torno a fines de agosto o principios de septiembre de 1563. Esto, a su vez, se relaciona con la otra señal profética resaltada en la estrofa XVII, 87, la onomástica.

Hasta ahora, se ha dado por sentado que Bernardo de Balbuena recibió su nombre de pila simplemente por ser el de su padre, sin caer en la cuenta de que, desde la Alta Edad Media, la predilección por la repetición del nombre paterno está ligada a la primogenitura, lo que no solo no ocurre en este caso, sino que se complica con la ilegitimidad. Esto apunta a la existencia de un elemento coadyuvante de esa elección nominal, que, según una práctica creciente en la época, bien pudo ser la cercanía del nacimiento a la fiesta de san Bernardo de Claraval, celebrada el 20 de agosto. Esta hipótesis onomástica 
queda prácticamente corroborada por el hecho de que, a su muerte (ocurrida el 11 de octubre de 1627), Balbuena "mandó su hacienda a la Iglesia, con cargo de que se labrase una capilla al señor san Bernardo para Sagrario ${ }^{42}$, y en ella se colocasen sus huesos, dotando la lámpara del aceite que pudiera gastar cada año, y en cada primer domingo de mes, se le dijese una misa cantada, y el día de señor san Bernardo otra, con sermón y vísperas, como todo se hace" (Torres Vargas, ed. Tapia 463; ed. Acosta y Coll 271; véanse también Blanco 11 y Campo Lacasa 69). Esto, además, explica mejor por qué el poeta sitúa al mismo nivel la coincidencia onomástica y la circunstancia astrológica, puesto que ambas habrían derivado, en último término, de su fecha de nacimiento.

Si consideramos, pues, que este tuvo lugar alrededor del 20 agosto de 1563, en la fecha del primer documento, el 8 de abril de 1584, Bernardo de Balbuena tendría veinte años y seis meses (lo que concuerda con la apreciación del propio autor en 1584 de ser "de hasta veinte y un años"); y, en la fecha del segundo documento, el 8 de noviembre de 1595, tendría treinta y dos años y tres meses. De este modo, el "poco más o menos" de los documentos sería, para el primero de los casos, poco menos de veintiuno, y, para el segundo, poco menos de treinta y tres, lo que supone un perfecto encaje de las piezas de este rompecabezas cronológico.

\section{EL DESTINO DEL POETA}

Podría objetarse a todo lo anterior que Balbuena se está limitando a emplear dos tradicionales recursos retóricos, los argumenta a nomine y a tempore. Se trataría, entonces, de un mero ejercicio de enaltecimiento personal, del que

42 De los cuatro Bernardos canonizados en la época (de Viena $\uparrow$ 842, degli Uberti o de Parma $\uparrow 1133$, de Menthon o de Aosta $\uparrow 1008$ y de Claraval $\uparrow 1153)$, el san Bernardo por defecto era y sigue siendo el último. De hecho, en los santorales españoles del siglo XVI solo se lo recoge a él, mencionado como "san Bernardo abad" o simplemente "san Bernardo", entre los santos de agosto (p. ej. Vega y Lilio 371r-374r). Solamente en la rama conocida como Flos Sanctorum renacentista aparece entre los santos de enero un homónimo, dentro de un grupo de mártires franciscanos en Marruecos, pero únicamente a partir de la edición de 1556 ( $c f$. Vega y Lilio 167r-168v), para desaparecer en la última impresión, la sevillana de 1580 (para este y los demás santorales hispanos descendientes de la Legenda aurea de Jacobo de Vorágine, véase Aragüés, "Los flores sanctorum" y "La difusa autoría"). 
no cabría fiarse mucho ni, en consecuencia, extraer precisiones cronológicas. Ahora bien, incluso dejando al margen que, ante semejante conjetura, el peso de la prueba recaería sobre quien acusase al poeta de insincero, la manera en la que esos datos se ofrecen no incurre en vanagloria, ya que no son de por sí objeto de encomio, sino simples constataciones explicativas de la particular conexión que une al poeta con lo poetizado, un aspecto fundamental en un poema en el que "La inclusión del 'yo' que se denomina explícitamente 'autor' es de tal modo importante, que toda lectura de El Bernardo que no la considere, resulta insuficiente" (Triviños 321).

Ese poder vinculante se aplica a ambos loci. En el caso del locus a nomine, este no apela aquí a razones genealógicas (laudatio e genere, $c f$. Lausberg 1: 217), sino al clásico principio nomen omen, en adnominatio consagrada por Plauto en Persa, v. 625: "Nomen atque omen quantivis iamst preti" $(111)^{43}$, salvo que en este caso no se basa en la tradicional interpretatio nominis, mediante una etimología ya sea real o aparente (argumentum a nota vel etymologia, $c f$. Lausberg 1: 332), sino en la homonimia, que actualiza una antiquísima creencia antroponímica: "Os laços de homonímia fazem reviver cada morto através de seu nome reencarnado. O novo portador do nome encontra-se religado [...] a seu epônimo" (Offroy 121). Esto enlaza además con el pasaje, subrayado ya por Triviños (322-23), en que se describe el escudo de Bernardo del Carpio, cuyo lema, en orla, reza: "A otro de su nombre está guardado / el romper con la pluma este nublado" (El Bernardo, II, 31, 7-8 $)^{44}$.

Respecto del locus a tempore, la precisa mención de la conjunción magna contrasta con la inconcreta del "astro infeliz" que hace que la grandeza del héroe hispánico "fuese / corta de voz y de valor sobrado" (II, 30, 3-4), siendo su fama "pobre de ventura" $(29,5)^{45}$, hasta que ese futuro homónimo sea la "pluma de estilo moderado" $(31,6)$ que la haga volar de nuevo y "hermosa y

$43 \quad C f$. Fontaine (28 y 92-94). A este respecto, téngase en cuenta que, en la tradición romana, "L'omen est, dans son sens strict, le présage entendu. Il intéresse l'individu et la vie de tous les jours. [...] L'omen, avertissemente envoyé par les dieux pour guider les hommes, confirme ceux-ci dans leurs entreprises ou bien les en détourne" (Bloch 82).

$44 \quad$ Respecto de este entramado profético, sobre "den extradiegetischen, nach dem Autor stilisierten Erzahler", véase Friedlein (336-338).

45 ¿Estaría refiriéndose Balbuena implícitamente al melancólico Saturno? Muy poco después destaca solo la influencia natal del belicoso Marte y de la amorosa Venus: "que en su real nacimiento dio una idea / de su furor la quinta esfera al suelo, / y otra de afable amor el tercer cielo" (II, 32, 6-8). 
clara al cielo la levante" $(31,2)$. De este modo, la configuración celeste que preside el nacimiento de Balbuena combina el concepto mántico de prodigium 'fenómeno raro o excepcional' (cf. Bloch 88) con la idea de kaıpó (cf. Lausberg 1: 327-329), que Cicerón describía así en De inventione: "Occasio autem est pars temporis habens in se alicuius rei idoneam faciendi aut non faciendi opportunitatem" (35; lib. I, cap. xxvii, § 40).

La idoneitas es, en este caso, la que ambas circunstancias prestan, a su juicio, al propio Balbuena, de tal modo que no se desprende de ello una laudatio, sino una adcequatio entre el autor y su tema. Esta se halla inscrita en él (según la terminología astrológica coetánea) mediante signa o señales que prcesignificant 'anuncian' o, más propiamente, signant 'señalan' los futura, los sucesos por venir. En este caso, el señalamiento se basa en la doble relación con Bernardo del Carpio que establecen la igualdad de nombre y la semejanza de configuraciones astrales, de modo tal que ambas signationes se relacionan de forma inextricable con la similitudo, pues, como explica Foucault, "Il n'y a pas de ressemblance sans signature. Le monde du similaire ne peut être qu'un monde marqué" $(41)^{46}$. Por ello, como señala Triviños, "El encuentro del guerrero con el escritor del mismo nombre se produce así en la forma y en el tiempo anunciados por las divinidades" (324 y cf. 327), a las que hay que añadir los astros.

Tales marcas prefiguran el destino del poeta, que no se limita a seguir una inclinación ${ }^{47}$; ni siquiera, por importante que esto sea, a responder a una vocación, sino que, desde su propio punto de vista, asume una verdadera misión. Se trata, pues, de un caso palmario de amor fati, el cual va más allá de la aceptación del propio destino, al estilo del resignado fatalismo estoico (cf. Lindberg 88), para convertirse en una asunción más bien exultante, que

46 Compárese el siguiente pasaje del Lepolemo (1521), de Alonso de Salazar: "Y teniéndole la infanta de la mano, a la raya de la lumbre, viole el señal que el Caballero de la Cruz tenía en el brazo, que parecía al suyo y díjole: -Mi señor, este lunar vos me lo habéis hurtado-. Y sacó su brazo y mostrole el suyo, que ninguna diferencia había del uno al otro, y díjole: -Señor, paréceme que Dios nos señaló a los dos de un señal para ser los dos una persona mesma-" $(129 \mathrm{v}$; cap. cxliv).

47 Recuérdese que, según la doctrina ortodoxa, las estrellas inclinan, pero no obligan (Hurtado 24-27). Así lo recogen autores como Calderón en La vida es sueño: "porque el hado más esquivo, / la inclinación más violenta, / el planeta más impío, / sólo el albedrío inclinan, / no fuerzan el albedrío" (144-45; jornada I, vv. 787-91) y Lope de Vega, entre burlas y veras, en las Rimas de Tomé de Burguillos: "No digo yo que fuerzan las estrellas; / que inclinan digo; pero tú no quieres / por tu elección ni porque inclinan ellas" (404; núm 98, vv. 9-11). 
puede vincularse a la connivencia entre el destino y el esfuerzo, expresada por las antiguas máximas audentis (o fortis) fortuna iuvat y faber quisque fortunce suce ${ }^{48}$. Esfuerzo que, como declara el pareado final de la octava XVII, 89, el primer Bernardo (el del Carpio), llevó a cabo, bajo la conjunción magna de 809 , mediante su "heroica espada" 49 , mientras que su cantor, el segundo Bernardo (el de Balbuena), lo realizó, a partir de la conjunción magna de 1563, mediante su "humilde pluma"50.

Al igual que en la profecía de Apolo, Balbuena se representa a sí mismo en la visión de Alcina como el poeta que devolverá a Bernardo del Carpio su merecida fama ( $c f$. Friedlein 331-32). Las octavas 29 a 31 responden a la idea ciceroniana de la necesidad que tienen los héroes de poetas que canten sus hazañas para ser recordados, que Balbuena desarrolla en su Compendio apologético en alabanza de la poesía (incluido en la Grandeza mexicana 252; cf. Triviños 331), donde remite de forma expresa a su fuente, el Pro Archia 23-24, de Cicerón. Así, un precedente interesante, acaso inmediato, encontramos en el Affrica IX, 53-64, de Petrarca, donde, en boca de Ennio, se versifican las palabras que el mismo Cicerón atribuye a Alejandro Magno en alabanza de Homero, al haber encontrado el sepulcro de Aquiles y el propio Petrarca su presenta como quien cantará las hazañas de Escipión.

A este paradigma épico se le debe añadir el modelo horaciano del panegírico, plasmado en la Ode ad Mcecenatem (Carmina I, I; ed. Shackleton Bailey 2), capaz de equiparar al encomiado, "Mæcenas, atavis edite regibus, / o et præsidium et dulce decus meum" (vv. 1-2), y al encomiador: "si me lyricis vatibus inseres, / sublimi feriam sidera vertice" (vv. 35-36). A ello puede sumarse, aunque de modo implícito, otro motivo horaciano, el de la inmortalidad de la propia obra poética, "monumentum aere perennius" (Carmina III, xxx, 1; ed. Shackleton Bailey 109). Ambos motivos se funden en el soneto panegírico dedicado por Francisco de Medina al marqués de Tarifa a propósito "de las rimas de Fernando de Herrera", cuyo dedicatario

48 Se trata de un planteamiento bien atestiguado en el período (Brendecke y Vogt 2, 4, 121-22, 186; Montaner, "Rufo astrólogo" 182 y 186).

49 El epíteto no se le aplica en los versos citados, pero sí en III, 82, 2 y en XIX, 103, 2 .

50 Esto supone una reconfiguración del tópico de las armas y las letras, entre las cuales se da al mismo tiempo una disociación y una correlación (cf. Triviños 327-32). 
era, siendo posible que Balbuena lo conociese $\mathrm{e}^{51} \mathrm{y}$ con cuyo planteamiento, en todo caso, coincide plenamente:

Las torres, cuyas cumbres levantadas, claríssimo Marqués, miráis al cielo; las colunas que Alcides en el suelo por término dexó de sus jornadas, serán al fin por tierra derribadas i cubiertas de olvido en negro velo, qu'el tiempo tiene a muerte i triste duelo nuestras mortales obras condenadas. Mas el alto, el eterno monumento qu'el ingenio divino de Fernando os fabrica con arte milagrosa, siglos i siglos durará sin cuento, vuestro nombre i el suyo celebrando de donde sale el Sol a do reposa (Herrera 177).

\section{CRONOGRAFÍA, PROGNOSIS Y AUTORÍA}

La inserción de una referencia astrológica tan específica y, por así decir, técnica, podría considerarse, desde la perspectiva de un lector ucrónico, como un elemento impropio de la fabulación épica. Uno de esos aspectos en los que el deber-ser poético habría convenido que desplazase al ser histórico, según pedía Aristóteles en celebérrima reflexión de su Poética:

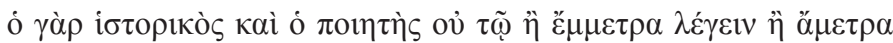

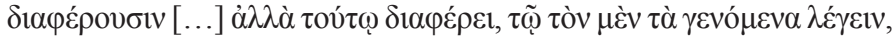

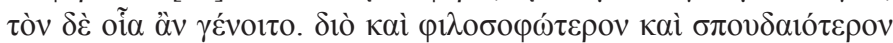

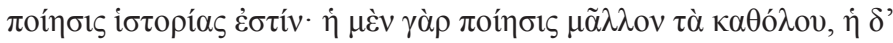

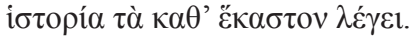

51 Sobre la probable influencia de Herrera en Balbuena, al menos respecto de los criterios prosódicos, véase Zulaica (459). 
pero el historiador y el poeta no se diferencian por contar las cosas en forma versificada o sin versificar [...]; sino que esto establece la diferencia: que uno cuenta lo que ha sucedido y otro, en cambio, lo que podría suceder. Y así la poesía es más filosófica y elevada que la historia; pues la poesía refiere [las cosas] más bien conforme a lo universal, pero la historia, conforme a lo particular (1451a36-1451b7; ed. Kassel 15).

Sin embargo, la percepción que la temprana modernidad tenía de la pertinencia de esta clase de indicaciones era muy otra, ya que la inserción de referencias astrológicas no constituye ninguna rareza en su literatura, a veces con formulaciones extraordinariamente precisas y con exposiciones tan técnicas como la que aquí ofrece Balbuena o incluso más. La propia conjunción magna aparece mencionada en diversas ocasiones. Así ocurre, aunque con un claro rechazo sobre sus supuestos efectos, en los Coloquios de Palatino y Pinciano (ca. 1550) de Arce de Otálora, quien se inspira (sin citarlo) en el capítulo IV del Tractato contra li astrologi de Savonarola:

\begin{abstract}
Aunque no hobiese otro testimonio contra ellos más de las mentiras que han dicho los principales dellos, bastan para su confusión. [...] Abraham, judío, que fue otro de los más estirados, afirmó que después del año de mil y cuatrocientos y cuarenta y cuatro, en el cual había de ser la conjunción de Júpiter y Saturno en Cancro, había de nacer el Mesías y librar el pueblo hebraico, porque dice que en semejante conjunción libró Moisén al pueblo de Israel de Egipto. Y ha pasado esta conjunción, y otra en el año de 1464, y no solamente no han tenido libertad ni ha venido su Mesías, antes han sido perseguidos y atribulados tanto que después de la destruición de Jerusalén no lo han sido más, pues los Reyes Católicos los echaron de sus reinos y fundaron contra ellos el Santo Oficio de Inquisición, y los otros príncipes cristianos han hecho lo mismo (2: 1001; XII, 4).
\end{abstract}

Aparece también, aunque bajo la forma de conjunción media (es decir, la de Saturno y Marte), en los Coloquios espirituales y sacramentales de González de Eslava, para explicar la peste que asoló México en 1576:

Celo. La pésima corrupción ¿de qué nació y en qué parte? 
SABER. Nació, por extraño arte,

de sola una conjunción

de Saturno y el dios Marte.

Celo. ¿A cosas tan levantadas

suben las humanas ciencias?

SABER. La salud y las dolencias

muchas veces con causadas

del cielo y sus influencias (XIV, 157).

Sin embargo, no se trata solo de menciones propias de la literatura doctrinal. En los autos de Calderón hay varias referencias a dicha posición astral, en relación con la estrella de Belén, mientras que, en la comedia de Juan de la Cueva La constancia de Arcelina (1579), el gran mago Orbante comenta los efectos de una conjunción entre el Sol y Marte (27). Se hallan, además, menciones de la conjunción magna con valor figurado en diversos autores, como Lope, Quevedo, Salas Barbadillo o Villamediana.

Al margen de las alusiones generales y de las que inciden particularmente sobre este fenómeno, las indicaciones astrológicas constituyen una constante propia de la épica áurea, bajo la forma tanto de cronografía como de prognosis. La primera la definía así, coetáneamente, el rétor Jiménez Patón, en su Mercurius Trimegistus: "Chronographia est temporis descriptio. Tale est illud Virgilii: Vertitur interea ccelum, et ruit Oceano nox [Eneida II, 250]. Et huiusmodi descriptiones ad periphrasim pertinent" (263v). En la épica áurea, esa perífrasis era usualmente mítico-astrológica, como puede apreciarse en Ercilla, La Araucana, XII, 33 y 299-303 o XV, 513-20; Camões, Os Lusíadas II, 72, o Rufo, La Austriada, IV, 56; V, 72; VI, 38; XIII, 68 y 72-73; XIX, 10; XX, 54 y 97 (Montaner, "La cronografía táurica"), siendo tan habitual que Mercedes Blanco ha llegado a considerarla una de las marcas del género (175). En El Bernardo puede hallarse, por ejemplo, en las octavas 89, 154, $177-79$ y $198-99$ del canto cuarto, o 134 y 171 del quinto.

En cuanto a la prognosis, la inclusión de predicciones por medio de un personaje masculino o femenino caracterizado a medias entre el nigromante, el teúrgo y el astrólogo, es otro recurso frecuentísimo en el género, a partir del Fitón de La Araucana (como han estudiado Nicolopulos, Vilà, Peredo y Lara). En particular, en La Austríada, el mago Xíloes, además de recurrir a la nigromancia, fundamenta su predicción sobre la batalla de Lepanto en un detallado y preciso comentario astrológico (XXII, 76-84), que se basa en una sinastría o comparación entre cartas astrales, en esta ocasión las 
correspondientes a la víspera de la batalla y a los respectivos temas natales de Carlos V, don Juan de Austria y Felipe II (Montaner, "Rufo astrólogo" 18486). En El Bernardo, la astrología toma parte, aunque de forma imprecisa, en la profecía pronunciada por el "mago anciano" Tlascalán en XVIII, 161-82 (véanse especialmente 163-64), mientras que la cosmografía y la astrología se conjugan en la minuciosa écfrasis de las bóvedas pintadas del palacio de Morgana, en I, 221-31; en el discurso del rey de Persia y en la respuesta del "sabio francés" Malgesí en XVI, 194-213, y en el viaje estratosférico del mismo en XVII, 1-33.

Justamente, el ámbito en el que se combinan la cronografía (como especificación perifrástica del punctus temporis) y la prognosis es en la figura genetlíaca o carta astral natalicia, ya que, por un lado, sirve para fijar (con una precisión inviable en la época por otros medios) el momento del nacimiento y, por otro permite, augurar determinados aspectos sobre el carácter y futuro del recién nacido. El factor profético se documenta en numerosos textos, ya que se relaciona con el tradicional componente prodigioso y oracular vinculado al nacimiento del héroe ( $c f$. Rank 79). En ocasiones, esta referencia alude a fenómenos como eclipses, que se enfocan más bien desde el punto de vista de los portentos naturales que de lo estrictamente astrológico, pero no faltan casos en que esta perspectiva es explícitamente evocada. Posiblemente el tema natal más célebre de la literatura del Siglo de Oro sea el de Segismundo, que da pie a toda la trama de La vida es sueño, aunque en este caso apenas hay detalles técnicos ${ }^{52}$. No así en el del caballeresco Libro de Platir (1533), donde la carta astral de su epónimo protagonista se presenta con bastante nitidez, como ha estudiado Miriam Palacios. El mismo Balbuena utiliza este recurso, pero no con su héroe homónimo, sino con otros dos de los personajes de El Bernardo, extensamente con Arcangélica en XIV, 15-18, y de modo muy sintético con el aristócrata y alquimista Arnaldo de Espurg, cuyo autoanálisis nos servirá de muestra:

52 Frederick De Armas ha propuesto que, junto a otros fenómenos astrológicos (varios eclipses ocurridos en el año 1605, uno solar y dos lunares, y a la nova de 1604 estudiada por Brahe), Calderón tenía en mente la conjunción magna máxima en Sagitario de 1603 al componer La vida es sueño, que relaciona con el nacimiento del nuevo monarca, Felipe IV, lo cual resulta altamente improbable, a la vista del argumento de dicha comedia. Para el papel de la astrología en la misma, baste remitir ahora al reciente trabajo de Marta Oria de Rueda. 
Conde Arnaldo de Espurg, si en los Estados

Bajos de mí tenéis noticia alguna, debajo algunos signos marañados rico nací con infeliz fortuna:

a Mercurio combusto en los airados rayos del Sol y la inconstante Luna en el noveno ángulo nocturno, triste y lóbrega casa de Saturno (XV, 96).

En cuanto a la presentación de la carta astral del autor mismo, no nos consta ningún ejemplo indubitable. Lo más cercano que conocemos son las indicaciones que da Quevedo en su conocido romance burlesco sobre su propio nacimiento (con el viejo de Abenámar y las endechas "Pariome mi madre" como trasfondo):

Pariome adrede mi madre,

¡ojalá no me pariera!,

aunque estaba cuando me hizo

de gorja Naturaleza.

Dos maravedís de luna

alumbraban a la tierra, que, por ser yo el que nacía, no quiso que un cuarto fuera. Nací tarde, porque el sol tuvo de verme vergüenza, en una noche templada, entre clara y entre yema. Un miércoles con un martes tuvieron grande revuelta, sobre que ninguno quiso que en sus términos naciera. Nací debajo de Libra, tan inclinado a las pesas, que todo mi amor le fundo en las madres vendederas. Diome el León su cuartana, diome el Escorpión su lengua, Virgo, el deseo de hallarle, 


\section{y el Carnero su paciencia ${ }^{53}$.}

En este caso, las únicas indicaciones astrológicas (y, por tanto, cronográficas) seguras son el nacimiento bajo el signo de Libra, la hora solar aproximada (hacia la medianoche) y la fase de la Luna (dos maravedís, esto es, un ochavo, correspondiente al cuarto día del mes lunar), ya que los demás elementos parecen tener un valor meramente figurativo, aunque esto solo podrá determinarlo un análisis más detallado ${ }^{54}$. Un ejemplo mucho más cercano al de Balbuena parece ser el de Lope, quien, en La Dorotea (280; IV, I), pone en boca de Fernando unas referencias a su tema natal que, por la condición de alter ego del autor que posee dicho personaje, varios estudiosos han considerado como el propio de Lope, hasta el punto de llegar a usarlo para fijar el nacimiento del fénix de los ingenios el día 3 de diciembre de 1562, entre las 14:30 y las 15:00 horas ${ }^{55}$. El paralelismo sería extremadamente interesante, en relación con la ya comentada autorreflexividad autorial, si no fuera porque en el texto de Lope no hay tal. En primer lugar, porque, al contrario de lo que ocurre con Quevedo, aquí el dato se atribuye a un personaje y no al autor implícito (como reflejo intradiegético del autor empírico), inexistente, claro está, en un diálogo como es La Dorotea. En segundo lugar, porque esa carta astral

53 Quevedo, Obra poética 2: 298-99; núm. 696, vv. 1-24 (texto de C) = Parnaso español 1: 984-85; n. ${ }^{\circ}$ 469, vv. 1-24.

$54 \quad$ Partiendo de los datos solar y lunar, y de la noticia de que Quevedo había nacido el día de los Estigmas de san Francisco (transmitida por el propio autor en una carta a su amigo don Sancho de Sandoval, fechada en Madrid a 31 de mayo de 1639), Rivas sitúa su nacimiento en la madrugada del miércoles 14 de septiembre de 1580. El martes 13 fue, en efecto, el cuarto día del mes lunar, según las efemérides modernas. Coetáneamente, Chaves (203) situó la luna nueva el 8 de septiembre de 1580, por lo que el cuarto día del siguiente mes lunar fue el 12, lo que se puede compaginar con las conclusiones de Rivas. Sin embargo, la carta astral no arroja correspondencias determinantes con todos los signos mencionados en el romance. El intento de Estadella de fijar la hora (a partir del trabajo de Rivas), tomando como hitos el ascendente en Leo y el medio cielo en Aries, es compatible con lo que dice el romance, pero este no permite, en rigor, establecer una razón astrológica para que Quevedo destaque esos signos, mientras que, en cualquier caso, la alusión a Cáncer carece de correlato en la carta astral.

55 El pasaje ha sido comentado (partiendo siempre de la premisa, puramente conjetural, de que el horóscopo de Fernando es el del mismo Lope y sin tener en cuenta los paralelos citados a continuación) por Millé, McCready y Vicente García ("Lope y la polémica sobre astrología" 227-32, y "Lope de Vega como astrólogo" 1941-45), a quien se debe la concreción horaria recogida en el texto. Las conclusiones del último han sido aceptadas en la reciente biografía del reconocido lopista Sánchez Jiménez, Lope: El verso y la vida 40, y en su artículo "Algunas metáforas astrológicas" 170. 
no es un préstamo personal del creador a su personaje, sino un empréstito de su biblioteca.

En efecto, el cálculo precitado se basa en la interpretación errónea o forzada de varios de los datos que ofrece el texto, los cuales, además, le habían servido ya de base a Lope para el soneto "La parte doce de los peces de oro", incluido en La Circe (1292), dedicado, esta vez, a Marcia Leonarda ${ }^{56}$, y más tarde para otro integrado en las Rimas de Tomé de Burguillos (404; núm. 95), aunque allí de forma hipotética, puesto que el (fingido) poeta no comparte esta figura astral: "Si en la parte duodécima tuviera / de los Peces la Luna, Juana mía..." $57 \mathrm{Si}$ el yo lírico lopesco, su doble narrativo y su heterónimo no nacieron bajo las mismas condiciones estelares, y aun así estas se toman como referentes, no solo del personaje en cuestión, sino también de su respectiva amada (Lope y Leonarda, Fernando y Dorotea, Burguillos y Juana), es porque esa situación (que implica de nuevo una sinastría) no tiene nada que ver con el propio Lope, sino que es un caso de manual de astrología hábilmente explotado por el poeta en virtud de las asociaciones temáticas y argumentales que permitía ${ }^{58}$.

Regresando al filósofo, señalaba este, a continuación del pasaje citado al inicio del presente apartado, que

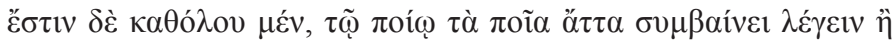

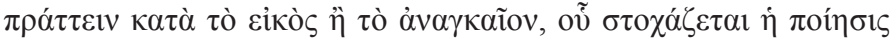

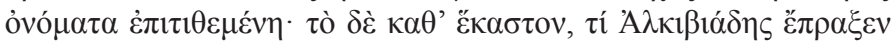
ì $\tau$ ध́ हैं $\alpha \theta \theta \varepsilon v$.

Se plantea conforme a lo universal a qué tipo de hombres les conviene

56 Blecua, Obras poéticas 1292 y 1392, relacionó ya los tres pasajes lopescos aquí comentados. Recientemente ha vuelto sobre ellos Sánchez Jiménez, “Algunas metáforas astrológicas" 172-75, donde reconoce certeramente la literaturización de Lope respecto de los personajes femeninos, pero no llega a advertirla en el propio yo lírico lopesco y en sus demás trasuntos literarios.

57 De entre los editores de las Rimas de Tomé de Burguillos (Blecua, Obras poéticas 1292 y Rimas 68; Rozas y Cañas 255-56; Cuiñas 309; Arellano 404-405) solo Arellano señala el paralelismo de La Dorotea, aunque ninguno menciona en este punto los trabajos que lo estudian. Anotan con diverso grado de detalle los aspectos astrológicos y, acaso por no tener el pie forzado de ajustarlos a una carta astral, ofrecen más acertadamente su sentido.

58 El caso aparece, concretamente, en los In Cl. Ptolomaei Commentaria del afamado Cardano (474; IV, vII, tx. 56 = Opera omnia 5: 344), como ya señaló Montaner ("Sobre el alcance..." 669-77). La versión más fiel a su modelo es la que da Lope en La Circe. 
decir o hacer tales o cuales cosas de acuerdo con lo verosímil o lo necesario, que es lo que pretende la poesía, aun poniendo nombres [a los personajes]; y conforme a lo particular, qué hizo Alcibíades o qué le ocurrió (Poética 1451b8-11; ed. Kassel 15).

En el caso de Balbuena, como en otros, la distinción aristotélica tiende a neutralizarse, pero si en la épica tradicional esto ocurre en virtud de la indistinción entre el ser histórico y el deber-ser poético ${ }^{59}$, en la épica áurea $\mathrm{y}$, muy en particular, en la cuestión aquí analizada, esto ocurre por la vía de la representación paradigmática. En efecto, al incluir su propia carta astral y personarse en su misma diégesis, bajo el modo de narrador intrusivo o invasivo, Balbuena se presenta a la vez como el individuo particular al que algo le aconteció - nacer bajo el influjo de la conjunción magna- y como el tipo de individuo a quien resulta propio hacer algo - celebrar, restaurándolas, las olvidadas glorias de su antiguo homónimo, el del Carpio-. La persona particular del poeta valdepeñero se presenta así, por vía de la fortuna astral y del hilo transtemporal establecido por los ciclos de las conjunciones magnas, como el paradigma mismo del cantor épico.

\section{EL QUE EN BUEN PUNTO NACIÓ}

Después de todo lo dicho, resulta claro que, desde su propia percepción, Balbuena había nacido en buen punto. La expresión aquí adoptada, como es bien sabido, constituye una de las variantes del epíteto astrológico aplicado al héroe del Cantar de mio Cid, siendo la otra "el que en buen ora nació" Durante el Siglo de Oro (según los datos del CORDE), el sintagma "en buen(a) hora" se empleaba como locución adverbial, sobre todo en expresiones desiderativas construidas con subjuntivo, como "sea en buen(a) hora", que sirve para desear cualquier buen suceso o, a menudo también, para intentar aminorar uno malo ${ }^{61}$. En consonancia, la expresión medieval "nació / nacido en buen(a) hora" no se documenta en este período, pero sí su correlativa

59 Como analiza Montaner, "Épica, historia, historificación".

60 Véanse Hamilton (174-176) y Montaner ("Tal es la su auze" 95-96).

$61 \quad$ La forma lexicalizada de esa frase, enhorabuena se documenta desde ca. $1480 \mathrm{y}$ puede actuar como adverbio o como sustantivo, cuando se refiere a la congratulación dada por una buena noticia. 
para el deceso, en la expresión "muera en buen(a) hora". Lo más parecido a la antigua fórmula genetlíaca que hemos podido encontrar es este pasaje de las Novelas en verso (ca. 1580) de Cristóbal de Tamariz: "Y cuando ya en buen ora sea parida" (274). Sí conservaba el sentido original la variante aquí adoptada, "en buen punto" 62 , como atestiguan las Coplas de la Natividad (1508) de fray Ambrosio Montesino: "Que de ser tú ya nascida / en buen punto" (215; n. ${ }^{\circ}$, vv. 1-8) y Los hechos del Cid (1568) de Jiménez de Ayllón: "vos fuistes en muy buen punto nacido" (canto VII, estrofa LVIII, v. 4576; ed. García Ruiz 339). Aunque en una formulación negativa, la expresión se halla también en esa misma obra, "En mal punto, don Diego, soy nascido" (VI, LXXIX, 4030; ed. García Ruiz 319); en Las mocedades del Cid, de Guillén de Castro: “¡En triste punto nací!” (104; jornada II, v. 2670) ${ }^{63}$, y en La vida es sueño, de Calderón. “¡Ay, príncipe desdichado, / y en triste punto nacido!" (197; acto III, vv. 2056-57).

Si Balbuena podía considerarse nacido en buen punto, no se debería particularmente a los buenos auspicios astrológicos de su carta astral, por más que a un fino conocedor de la astrología, como él era, no se le escaparía el alcance de la configuración astral que presidía su natalicio, que ya hemos visto comentada por Bateno de Malinas. En efecto, la manera en la que el poeta plantea la cuestión deja claro que, además de situar su nacimiento inequívocamente a fines de agosto de 1563, lo que implican las señales asociadas al mismo es su indeleble y casi inevitable conexión, tanto onomástica como

Este punto es el que Nebrija llamaba "Punto de tiempo. momentum, -i; instans" (123) y corresponde al sentido del clásico punctum temporis, que Fenucci definía así en 1586: "Sunt etiam idem momentum, instans, nunc, et punctum temporis [...] momentum pro ipso instanti uel pro aliqo tempore imperceptibili accipi potest. [...] momentum nihil aliud est quam illud individuum punctum quod temporis pręteritis finis est et initium futuris, a quo sit temporis continuatio per prius et posterior" (8; cap. III, $\S \S 1-3)$. Cf. la reflexión de Séneca en una de sus epístolas morales: "Et alioqui non possunt longa intervalla esse in ea re, quæ tota brevis est. Punctum est quod vivimus et adhuc puncto minus" (147; epist. XLIX, § 3), lo que Quevedo poetizaba así "Ayer se fue; mañana no ha llegado; / hoy se está yendo sin parar un punto" (Obra poética 1: 150; n. ${ }^{\circ}$ 2, vv. 9-10 = Parnaso español 1: 114; n. ${ }^{\circ}$ 54, vv. 9-10). La locución en buen punto pasó a significar también 'a punto'.

63 El editor, en nota al verso 2670, glosa “punto: 'momento', en el sentido astrológico de 'conjunción astral"', pero no hay tal; el punto, como acabamos de ver, es el punctum temporis o la hora. Aquí se trata del momento en que se produce el nacimiento, al que corresponde la carta astral del recién nacido, como señala el étimo de horóscopo $<$ lat. horoscŏpus $<$ gr. ஸ́робко́лоs, literalmente 'el que observa la hora'. 
cronográfica, con la batalla de Roncesvalles y los tiempos de Carlomagno $\mathrm{y}$-sobre todo- con la propia figura de Bernardo del Carpio.

\section{BIBLIOGRAFÍA}

Ailly, Pierre D’. Concordantia Astronomie cum Theologia; Concordantia Astronomie cum hystorica narratione; Elucidarium duorum precedentium. Ed. Johann Engel. Augustæ Vindelicorum: Erhardus Ratdolt, 1490.

Albumasar [= Abū Ma šar]. De magnis coniunctionibus. Ed. Yamamoto y Burnett. Leiden: Brill, 2000. 2 vols.

Alcabitıus [= al-Qabị̄̄̂̀] . Astronomie iudiciarie principia. Cum Joannis Saxonie commentario atque glossa, per magistrum Petrum Turrellum. Lugduni: opera M. Gilhelmi Huyon, impensis Batholomei Trot, [ca. 1520].

Antonio, Nicolás. Biblioteca hispana [nova] sive Hispanorum ...; duabus partibus continens. Romae: ex Officina Nicolai Angeli Tinassii, 1672.

Apiano, Pedro. Astronomicum Caesareum. Ingolstadii: in ædibus nostris [i. e. ipsius Petri Apiani], 1540.

ARAgÜÉs Aldaz, José. "Los flores sanctorum medievales y renacentistas: brevísimo panorama crítico". Literatura medieval y renacentista en España: líneas y pautas. Ed. Natalia Fernández Rodríguez y María Fernández Ferreiro. Salamanca: SEMYR, 2012. 349-61.

"La difusa autoría del Flos sanctorum: silencios, presencias, imposturas". El autor oculto en la literatura española. Siglos XIV a XVIII. Ed. Maud Le Guellec. Madrid: Casa de Velázquez, 2014. 21-40.

Arce de Otárola, Juan de. Coloquios de Palatino y Pinciano. Ed. José Luis Ocasar Ariza. Biblioteca Castro. Madrid: Turner, 1995, 2 vols.

Arellano, Ignacio (ed.). Lope de Vega. Rimas humanas y divinas del licenciado Tomé de Burguillos. Ed. Madrid - Frankfurt am Main: Iberoamericana - Vervuert, 2019.

Balbuena, Bernardo de. El Bernardo, o victoria de Roncesvalles. Ed. Martín Zulaica López. Pról. Alberto Montaner Frutos. Madrid: Ars Poetica, 2017, 2 vols.

Grandeza mexicana. Ed. Asima F. X. Saad Maura. Madrid: Cátedra, 2011.

Bateno de Malinas, EnRique [= Hendrik Bate van Mechelen]. The Astrological Autobiography of a Medieval Philosopher: Henry Bate's Nativitas (1280-81). Ed. Carlos Steel et alii. Leuven: Leuven University Press, 2018.

Blanco, Mercedes. Góngora heroico: Las Soledades y la tradición épica. Madrid: CEEH, 2012.

Blecua, José Manuel (ed.). Lope de Vega. Obras poéticas: Rimas; Rimas sacras; La Filomena; La Circe; Rimas humanas y divinas del licenciado Tomé de Burguillos. Ed. José Manuel Blecua. Madrid: Planeta, 1983.

, ed. Lope de Vega. Rimas de Tomé de Burguillos. Madrid: Planeta, 1976.

Bloch, Raymond. La divination dans l'Antiquité. Paris: Presses Universitaires de France, 1984. 
Brahe, Tycho. Astronomice instauratce progymnasmata. Uraniburgi; Pragæ: [s. n.], 1602.

BReCht, Martin. Martin Luther: His road to Reformation, 1483-1521. Philadelphia: Fortress, 1985.

Brendecke, Arndt, y Peter Vogt (eds). The End of Fortuna and the Rise of Modernity. Berlin: De Gruyter, 2017.

Burnett, Charles. “Abū Ma'shar". Encyclopaedia of Islam Three. 2007. http://dx.doi. org/10.1163/1573-3912_ei3_SIM_0032

Brunfels, Отto. De deffinitionibus et terminis Astrologice libellus. Ed. conjunta con Iulii Firmici Materni Iunioris Astronomicon libri VIII y otros tratados astrológicos. Basileæ: Ex officina Ioannis Hervagii, 1533. a2v-a6r.

Cacho Casal, Rodrigo. "Bernardo de la Vega y los poetas perdidos del Nuevo Mundo". Hispanic Review 87.1 (2019): 1-26.

Campanella, Tommaso. De Monarchia Hispanica discursus. Amstelodami: apud Ludovicum Elzevirium, 1640.

Campo Lacasa, Cristina. Historia de la Iglesia en Puerto Rico (1511-1802). San Juan de Puerto Rico: Instituto de Cultura Puertorriqueña, 1977.

Calderón de la Barca, Pedro. La vida es sueño. Ed. Fausta Antonucci. Barcelona: Crítica, 2008.

Cardano, Girolamo. “Aphorismorum astronomicorum segmenta septem”. Libelli quinque. Norimbergæ: apud Iohannem Petreium, 1547. 207v-306v.

"De exemplis centum geniturarum". Libelli quinque. Norimbergæ: apud Iohannem Petreium, 1547. 102v-182v.

"De iudiciis geniturarum". Libelli quinque. Norimbergæ: apud Iohannem Petreium, 1547, ff. 47r-81r.

In Cl. Ptolomcei de Astrorum Iudiciis Commentaria; De septem erraticarum stellarum qualitatibus atque uiribus liber; Geniturarum item XII exempla. Basileæ: ex Officina Henricpetrina, 1578.

Opera omnia in decem tomos digesta. Lugduni: sumptibus Ioannis Antonii Huguetani \& Marci Antonii Ravaud, 1663. 10 vols.

Castro, Guillén de. Las mocedades del Cid. Ed. Stefano Arata. Barcelona: Crítica, 1996.

Chaves, Jerónimo de. Chronographia o reportorio de los tiempos. Sevilla: Fernando Díaz, a costa de Juan Francisco de Cisneros, 1580.

Cicerón, Marco Tulio. Rhetorici libri duo qui vocantur De inventione. Ed. E. Stroebel. Leipizg: Teubner, 1915.

Cueva, Juan de la. La constancia de Arcelina. [1579]. Madrid: Sociedad de Bibliófilos Españoles, 1917.

Cuiñas, Macarena (ed.). Lope de Vega. Rimas humanas y divinas del licenciado Tomé de Burguillos. Madrid: Cátedra, 2008.

Dante Alighieri. La Divina Commedia. Ed. Anna Maria Chiavacci Leonardi. Milano: Mondadori, 2016. 3 vols.

De Armas, Frederick. "Segismundo/Philip IV: The Politics of Astrology in La vida es Sueño". Bulletin of the Comediantes 53.1 (2001): 83-100. 
Estadella, Juan. “El horóscopo de Quevedo”. Cuadernos de Quevedo 1 (2010): 2-24.

Etz, Donald V. "Conjunctions of Jupiter and Saturn". Journal of the Royal Astronomical Society of Canada 94 (August/October 2000): 174-178.

Faracovi, Ornella. "The Return to Ptolemy". A Companion to Astrology in the Renaissance. Ed Brendan Dooley. Leiden: Brill, 2014. 87-98

Federici Vescovini, Graziella. "The Theological Debate". A Companion to Astrology in the Renaissance. Ed Brendan Dooley. Leiden: Brill, 2014. 99-140.

Fenucci da Sassuolo, Lazzaro. Tractatus de momento temporis. Venetiis: ex Officina Ioannis Baptistæ Somaschi, 1586.

Fernández Juncos, Manuel. "D. Bernardo de Balbuena, Obispo de Puerto-Rico. Estudio biográfico y crítico”. [1883]. Ed. Raul Díaz Rosales. Analecta malacitana 30.2 (2007): $627-52$.

Fontaine, Michael. Funny Words in Plautine Comedy. Oxford: Oxford University Press, 2010.

Foucault, Michel. Les mots et les choses: Une archéologie des sciences humaines. París: Gallimard, 1966.

Friedlein, Roger. Kosmovisionen: Inszenierungen von Wissen und Dichtung im Epos der Renaissance in Frankreich, Portugal und Spanien. Stuttgart: Franz Steiner, 2014.

Fuzeau-Braesch, Suzel. L'astrologie. 3. a ed. Paris: Presses Universitaires de France, 1989.

García Ferrández, Miguel. Astrología personal. Madrid: Factoría Kepler, 1994.

García Ruiz, Aurora, ed. Edición crítica y estudio de Los famosos y heroicos hechos del Cid Ruy Díaz de Vivar (1568) de Diego Jiménez de Ayllón. 2021. Universidad de Zaragoza, tesis doctoral.

GaURICO, LuCA. Tractatus astrologicus, in quo agitur de proteritis multorum hominum accidentibus per proprias eorum genituras ad unguem examinatis. Venetiis: apud Curtium Troianum Navò, 1552.

Garibay y Zamalloa, Esteban de. Compendio historial de las chronicas y universal historia de todos los reynos d'España, Anveres: Christophoro Plantino, 1571. 2 vols.

Geneva, Ann. Astrology and the Seventeenth Century Mind: William Lilly and the Language of the Stars. Social and Cultural Values in Early Modern Europe. Manchester: Manchester University Press, 1995.

González Boixo, José Carlos. "Bernardo de Balbuena”. Diccionario Biográfico Español. Vol. 6. Madrid: Real Academia de la Historia, 2009. 600-603.

GonzÁlez DÁvila, Gil. Teatro eclesiástico de la primitiva iglesia de las Indias occidentales. Madrid: Diego Díaz de la Carrera, 1649-1655. 2 vols.

Hamilton, Rita. "Epic epithets in the Poema de Mio Cid". Revue de Litterature Comparée 26 (1962): 161-178.

Herrera, Fernando De. Algunas obras. [1578]. Ed. Begoña López Bueno. Sevilla: Diputación de Sevilla, 1998.

Isidoro de Sevilla. Etymologiarum sive Originum libri XX. Ed. W. M. Lindsay. Oxonii: e Typographeo Clarendoniano, 1911.

JuAn DE SAJONIA [= Jean de Saxe = Johannes Saxoniæ], Glossa : véase Alcabitius. 
Jiménez Patón, Bartolomé. Mercurius Trimegistus, sive de triplici eloquentia: Sacra, Española, Romana. Baeza: Pedro de la Cuesta Gallo, 1621.

Kepler, Johannes. De stella nova in pede Serpentarii. Pragæ: ex Officina Pauli Sesii, 1606. LAUSBERG, HeInRICH. Manual de retórica literaria: Fundamentos de una ciencia de la literatura. Vers. esp. José Pérez Riesco. Madrid: Gredos, 1966-1969. 3 vols.

Lanuza Navarro, Tayra. "La astrología como explicación científica de la historia. Los pronósticos españoles del siglo XVII". En Synergia: Jóvenes Investigadores en Historia de la Ciencia. Eds. Néstor Herrán, Josep Simón, Ximo Guillem-Llobat, Tayra Lanuza Navarro, Pedro Ruiz Castel y Jaume Navarro. Madrid: CSIC, 2007. 303-23.

“Astrological Literature in Seventeenth-Century Spain". The Colorado Review of Hispanic Studies 7 (Fall 2009): 119-136.

Kassel, Rudolf (ed.). Aristotelis de arte poetica liber. Scriptorum Classicorum Bibliotheca Oxoniensis. Oxford: The Clarendon Press, 1965.

LARA, Eva. "Del Orlando furioso a Las lágrimas de Angélica: La mujer del Orco como mágica heredera de Canidia y Ericto". Dicenda 34 (2016): 181-213.

Leo, Alan. Diccionario de astrología. 1905. Trad. Astrene Sued y Alena de Río, Barcelona: Edicomunicación, 1989.

León Pinelo, Antonio de. Anales de Madrid hasta el año de 1658. Madrid, Biblioteca Nacional, Mss/18298. http://bdh.bne.es/bnesearch/detalle/bdh0000135757

Anales de Madrid (desde el año 447 al de 1658). Ed. Pedro Fernández Martín. Madrid: Instituto de Estudios Madrileños (CSIC), 1971.

LeOPOLdo de Austria [= Leupoldus]. Compilatio de astrorum scientia, decem continentis tractatus. Augustæ Vindelicorum: Erhardus Ratdolt, 1489.

LindBerG, Bo. "Stoicism and Consolation". LIR.journal 4 (2015): 80-91.

McCready, Warren T. "Lope de Vega's Birth Date and Horoscope". Hispanic Review 28.4 (October 1960): 313-318.

Medina, José Toribio. Escritores hispanoamericanos celebrados por Lope de Vega en el Laurel de Apolo. Santiago de Chile: Imprenta Universitaria, 1922.

Messahala (ch) [= Māšāà allāh]. De ratione circuli et stellarum. Ed. conjunta con Cl. Ptolomoei Pheludiensis Alexandrini Quadripartitum y otros tratados astrológicos. Basileæ: Ex officina Ioannis Hervagii, 1533. 115-118.

Millé y Giménez, Juan. “El horóscopo de Lope de Vega”. Humanidades (La Plata) 15 (1927): 69-96.

Montaner, Alberto. “Tal es la su auze: El héroe afortunado del Cantar de mio Cid". Olivar, 10 (2007): 89-105.

“Sobre el alcance del 'ocultismo' renacentista”. Señales, Portentos y Demonios: La magia en la literatura y la cultura españolas del Renacimiento. Ed. Eva Lara y Alberto Montaner. Salamanca: SEMYR, 2014. 627-850.

"Épica, historicidad, historificación”. El Poema de mio Cid y la épica medieval castellana: Nuevas aproximaciones críticas. Ed. Juan-Carlos Conde y Amaranta Saguar. Papers of the Medieval Hispanic Research Seminar 75. London: Queen Mary University of London, 2015. 17-53. 
"Rufo astrólogo en La Austríada". En Adivinos, médicos y profesores de secretos en la España Áurea. Ed. Folke Gernert. Toulouse: Presses Universitaires du Midi, 2017. 175-190

"La cronografía táurica en Camões, Rufo y Góngora: Astrología y retórica". La razón es Aurora: Estudios en homenaje a la profesora Aurora Egido. Ed. José Enrique Laplana et alii. Zaragoza: Institución "Fernando el Católico", 2017. 375-89.

y Diego Navarro. "Manojo documental sobre Bernardo de Balbuena". RILCE 37.2 (2021): 728-792

Montesino, Ambrosio. Cancionero. Ed. Julio Rodríguez Puértolas. Cuenca: Diputación Provincial de Cuenca, 1987.

Morinus 6.2: Astrological Program Written in Python, Using the Swiss Ephemeris. Ed. Robert Nagy et alii. 2014.

NAвотн, Valentin [= Valentinus Naiboda]. Enarratio elementorum Astrologice. Coloniæ: Hæredes Arnoldi Birckmanni, 1560.

NÁJERA, ANTONIO DE. Summa Astrológica y Arte para enseñar hazer pronósticos de los tiempos. Lisboa: Antonio Álvarez, 1632.

NeBRiJA, ANTONIO DE. Vocabulario de romance en latín. Nuevamente corregido y augmentado. Sevilla: Juan Varela de Salamanca, 1516,

Nicolopulos, James. "Pedro de Oña and Bernardo de Balbuena read Ercilla's Fitón" Latin American Literary Review 26.52 (July-December 1998): 100-19.

The Poetics of Empire in the Indies: Prophecy and Imitation in La Araucana and Os Lusiadas. University Park: Pennsylvania State University Press, 2000.

North, John. Cosmos: An illustrated history of Astronomy and Cosmology. Chicago - London: The University of Chicago Press, 2008.

NúÑez de Zamora, Antonio. Liber de Cometis; El juyzio de la máxima conjunctión del año de 1603. Salamanticæ: in ædibus Antoniæ Ramirez, 1610.

Ofek, Eran O. Mutual Planetary Conjunctions and Occultations. Tau Astronomy Club, astroclub.tau.ac.i1/ephem/PlanetsConj/.

Offroy, JeAn-Gabriel. "O prenome e a identidade social: do projeto social e familiar ao projeto parental”. Cronos, 5-6 (2004/2005): 119-133.

Oria de Rueda, Marta C. "El determinismo astral frente a la libertad en La vida es sueño de Calderon de la Barca". Hecho Teatral 20 (2020): 39-70.

Palacios Larrosa, Miriam. "El retrato astrológico del héroe: El caso de Platir". De la magia al escepticismo: Literatura, ciencia y pensamiento en los siglos XVI-XVIII. Ed. Mariona Sánchez Ruiz. Girona: Documenta Universitaria, 2018, pp. 155-71.

Peredo Betancourt, Luis Miguel. Brujas épicas: Ericto como fuente literaria. Tesis doctoral. Universitat de Girona, 2015.

Petrarca, Francesco. L'Afrique = Affrica . Ed. y trad. Pierre Laurens. Paris: Les Belles Lettres, 2006-2018, 2 vols.

Peuerbach, Georg. Nova theorica planetarum. Ed. Petrus Apianus. Venetiis: per Petrum de Nicolinis, sumptu Melchioris Sessæ, 1551. 
Plauto. Persa. Ed. G. Goetz y F. Schoell. T. Macci Plauti Comoedice, fasc. V, Lepizig: Teubner, 1896. 70-125.

Ptolomeo. Tetrabiblos. Ed. F. E. Robbins. Cambridge, Mass. - London: Harvard University Press - William Heinemann, 1940.

Porras Muñoz, Guillermo. "Nuevos datos sobre Bernardo de Balbuena”. Revista de Indias 41 (1950): 591-95.

Quevedo, Francisco de. Obra poética. Ed. José Manuel Blecua. Madrid: Castalia, 19691981.4 vols.

El Parnaso español. Ed. Ignacio Arellano. Biblioteca Clásica 38. Madrid: Real Academia Española, 2020. 2 vols.

Quintana, Manuel José. "Noticias del autor", en Bernardo de Balbuena, El Bernardo: poema heroyco. Segunda edición. Vol. I. Ed. Manuel José Quintana. Madrid: Imprenta de Sancha, 1808. I-IV.

RAnK, Otтo. El mito del nacimiento del héroe. Trad. Eduardo A. Loede, rev. Enrique Butelman. Barcelona - Buenos Aires: Paidós, 1991.

Real Academia Española. Diccionario [de Autoridades] de la Lengua Castellana. Madrid: Francisco del Hierro, 1726-1739. 6 vols.

Reinhold, Erasmus. Prutenica tabula cælestium motum. Tubingæ: per Vlricum Morhardum, 1551.

Riccioli, Giovanni Battista. Almagestum novum Astronomiam veterem novamque complectens. Bononiae: Hæredis Victorii Benatii, 1651, 2 t. en 3 vols.

Rivas-Cabezuelo, José Luis. "Sobre el nacimiento de Francisco de Quevedo". La Perinola: Revista de Investigación Quevediana 12 (2008): 231-35.

Rojas Garcidueñas, José. Bernardo de Balbuena: La vida y la obra. 2. ed. México: UNAM, 1982.

Rozas, Juan Manuel y Jesús Cañas Murillo (eds.). Lope de Vega. Rimas humanas y divinas del Licenciado Tomé de Burguillos. Madrid: Castalia, 2005.

Rubio Mañé, José Ignacio. "Bernardo de Balbuena y su Grandeza Mexicana". Boletín del Archivo General de la Nación - 2época 1 (1960): 87-100.

"Noticias biográficas adicionales acerca de Bernardo de Balbuena". Boletín del Archivo General de la Nación - 2a época 7 (1966): 857-862.

Salazar, Alonso de. Lepolemo, llamado el Caballero de la Cruz. [1521]. Ed. Anna Bognolo y Alberto del Río. Zaragoza - Alcalá de Henares: Prensas de la Universidad de Zaragoza - Universidad de Alcalá, 2016.

SAmsó, Julio. "Māshāā' Allāh". Encyclopaedia of Islam: Second Edition. Volume 6: Mahk-Mid. Ed C. E. Bosworth et alii. Leiden: Brill, 1991. 710-712.

SÁnchez JimÉnez, Antonio. Lope: El verso y la vida. Madrid: Cátedra, 2018.

"Algunas metáforas astrológicas en Lope de Vega: las sinastrias en El cuerdo loco (1607), La Circe (1624) y las Rimas de Tomé de Burguillos (1634)". "Los cielos se agotaron de prodigios": Essays in Honor of Frederick A. De Armas. Ed. Christopher B. Weimer et alii. Newark: Juan de la Cuesta, 2018. 167-79. 
Schoener, Gustav-Adolf. “The Coming of a 'Little Prophet': Astrological Pamphlets and the Reformation”. Esoterica 6 (2004): 59-66.

SÉnECA, Lucio Anneo. Epistulce morales ad Lucilium. Ed. Otto Hense. Lepizig: B. G. Teubner, 1938.

Shackleton Bailey, D. R., ed. Q. Horati Flacci Opera, Suttgart: B.G. Teubner, 1985.

Stade, JEAn [= Johannes Stadius]. Ephemerides novee et auctce. Coloniae Agrippinae: apud hæredes Arnoldi Birckmanni, 1560.

Switzer, Eric R. (dir.) Lambda-tools: Conversion Utilities. Astrophysics Science Division at NASA/GSFC. https://lambda.gsfc.nasa.gov/toolbox/tb_converters_ov.cfm.

TAmariz, Cristóbal De. Novelas en verso. Ed. Donald McGrady. Charlottesville: Biblioteca Siglo de Oro, 1974.

Terukina Yamauchi, Jorge Luis. El imperio de la virtud: Grandeza Mexicana (1604) de Bernardo de Balbuena y el discurso criollo novohispano. Woodbridge: Tamesis Books, an imprint of Boydell and Brewer, 2017.

Tornamira, Francisco Vicente de. Chronographía, y repertorio de los tiempos, a lo moderno. Pamplona: Tomás Porralis de Saboya, 1585.

Torres Vargas, Diego de. Descripción de la isla y ciudad de Puerto Rico [...] enviada al Sr. Cronista Maestro Gil González Dávila. 1647. Ed. Alejandro Tapia y Rivera. Biblioteca histórica de Puerto Rico. San Juan: Márquez, 1854. 447-498. Ed. José Julián Acosta (transcr.) y Cayetano Coll y Toste (nn.). Boletín Histórico de Puerto Rico 4 (1917): 257-293.

Triviños, Gilberto. "Bernardo del Carpio desencantado por Bernardo de Balbuena”. Revista Chilena de Literatura 16/17 (octubre 1980-abril 1981): 315-38.

Van Horne, John. El Bernardo of Bernardo de Balbuena: A Study of the Poem with Particular Attention to its Relations to the Epics of Boiardo and Ariosto and to its Significance in the Spanish Renaissance, monográfico de University of Illinois Studies in Language and Literature 12/1 (1927).

"Documentos del Archivo de Indias referentes a Bernardo de Balbuena". Boletín de la Real Academia de la Historia 46 (1930): 857-876.

"El nacimiento de Bernardo de Balbuena". Revista de Filología Española 20 (1933): 160-168.

Bernardo de Balbuena: Biografía y crítica. Guadalajara (México): Font, 1940.

VAsco, EusEBIo. Valdepeñeros Ilustres: Apuntes Biográficos. Valdepeñas: La Voz de Valdepeñas, 1890.

Valdepeñas, cuna de la descalcez trinitaria: apuntes históricos. Valdepeñas: Imprenta de Mendoza, 1912.

VeGA, LoPe DE. La Circe, con otras rimas y prosas. [1624]. Obras poéticas. Ed. José Manuel Blecua. Madrid: Planeta, 1983. 915-1318.

La Dorotea. [1632]. Ed. Donald McGrady. Biblioteca Clásica 53. Madrid: Real Academia Española, 2011.

Rimas humanas y divinas del licenciado Tomé de Burguillos. [1634]. Ed. Ignacio Arellano. Madrid - Frankfurt am Main: Iberoamericana - Vervuert, 2019. 
Vega, Pedro de la y Martín de Lilio (eds.). Flos santorum: La vida de nuestro señor Jesu Christo y de su santíssima Madre y de los otros santos según la orden de sus fiestas. Ahora de nuevo corregido y emendado, y añadidas algunas vidas de santos. Alcalá de Henares: Juan de Brocar, 1558.

Vicente García, Luis Miguel. "Lope y la polémica sobre astrología en el Seiscientos". Anuario Lope de Vega 15 (2009): 219-43.

"Lope de Vega como astrólogo: Su horóscopo de Felipe IV para las justas poéticas toledanas de 1605 y el suyo propio en La Dorotea". La dinastía de los Austria: Las relaciones entre la Monarquía Católica y el Imperio. Ed. José Martínez Millán y Rubén González Cuerva. Madrid: Polifemo, 2011. 3: 1929-46.

VILÀ, LARA. "Han escrito cosas prodigiosas fuera de toda verdad: Magia y maravilla en la épica española del Renacimiento". Señales, Portentos y Demonios: La magia en la literatura y la cultura españolas del Renacimiento. Ed. Eva Lara y Alberto Montaner. Salamanca: SEMYR, 2014. 465-88.

Woody, Kennerly M. "Dante and the Doctrine of the Great Conjunctions." Dante Studies, with the Annual Report of the Dante Society 95 (1977): 119-34.

Yamamoto, Keijl y Charles Burnett. Abū Ma šar on Historical Astrology: The Book of Religions and Dynasties (On the Great Conjunctions). Leiden: Brill, 2000. 2 vols.

Zulaica López, Martín. Estudio y edición crítica y anotada de "El Bernardo o Victoria de Roncesvalles" de Bernardo de Balbuena. Tesis doctoral. Universidad de Navarra, 2019.

Zulaica López, Martín. "Bernardo de Balbuena. Vida y virtud, obra y fama”, Historia de las literaturas en México. Vol. 1 - El primer siglo de las letras novohispanas (1519-1624). Coord. Jessica C. Locke, Ana Castaño, Jorge Gutiérrez Reyna. México: UNAM, 2021. t. 2. 807-833. 